\title{
Leveraged Buyouts and Bond Credit Spreads
}

\author{
Feldhütter, Peter; Eisenthal-Berkovitz, Yael; Vig, Vikrant
}

Document Version

Accepted author manuscript

Published in:

Journal of Financial Economics

DOI:

10.1016/j.jfineco.2019.07.007

Publication date:

2020

License

CC BY-NC-ND

Citation for published version (APA):

Feldhütter, P., Eisenthal-Berkovitz, Y., \& Vig, V. (2020). Leveraged Buyouts and Bond Credit Spreads. Journal of Financial Economics, 135(3), 577-601. https://doi.org/10.1016/j.jfineco.2019.07.007

Link to publication in CBS Research Portal

\section{General rights}

Copyright and moral rights for the publications made accessible in the public portal are retained by the authors and/or other copyright owners and it is a condition of accessing publications that users recognise and abide by the legal requirements associated with these rights.

Take down policy

If you believe that this document breaches copyright please contact us (research.lib@cbs.dk) providing details, and we will remove access to the work immediately and investigate your claim. 


\section{Leveraged Buyouts and Bond Credit Spreads}

\section{Peter Feldhïtter, Yael Eisenthal-Berkovitz, and Vikrant Vig}

Journal article (Accepted manuscript*)

\section{Please cite this article as:}

Feldhütter, P., Eisenthal-Berkovitz, Y., \& Vig, V. (20२०). Leveraged Buyouts and Bond Credit Spreads. Journal of Financial Economics, 1333), 577-601. https://doi.org/10.1016/j.fineco.2019.07.007

DOl: https://doi.org/10.1016/j.jfineco.2019.07.007

* This version of the article has been accepted for publication and undergone full peer review but has not been through the copyediting, typesetting, pagination and proofreading process, which may lead to differences between this version and the publisher's final version AKA Version of Record.

Uploaded to CBS Research Portal: March २०२०

(ㄱ २०२०. This manuscript version is made available under the CL-BY-NC-ND 4.0 license http://creativecommons.org/licenses/by-nc-nd/4.0/ 


\title{
Leveraged Buyouts and Bond Credit Spreads*
}

\author{
Yael Eisenthal-Berkovitz ${ }^{\dagger}$ \\ Peter Feldhütter $\ddagger$ \\ Vikrant Vig§
}

Thursday $18^{\text {th }}$ October, 2018

\begin{abstract}
Recent decades have witnessed several waves of buyout activity. We find LBOs to be a significant concern for bondholders by showing that a) intra-industry credit spreads increase upon an LBO announcement, b) yields on bonds without event risk covenants are, on average, 21 bps higher than those on same-firm bonds with such covenants and c) structural models calibrated to historical LBO events imply an impact of 18-21bps on 10-year credit spreads. The impact is strongest in expansion periods and for bonds with maturities of 10-20 years.
\end{abstract}

Keywords: Credit Spreads, LBO risk, Structural Models, Leveraged Buyouts;

JEL: G12, G34

${ }^{*}$ We are grateful for comments from Patrick Augustin (discussant), Ramona Dagostino, David Lando, Anton Lines (discussant), Dragon Yongjun Tang (discussant), Lasse Heje Pedersen and seminar participants at the 4nations cup 2016 in Copenhagen, The CityU of Hong Kong International Finance Conference 2016, HEC-McGill Winter Finance Workshop 2017, EFA 2017, Lancaster University, Bocconi University, Bank of Portugal and Manchester Business School.

${ }^{\dagger}$ Arison School of Business, IDC Herzliya, email: yael.eisenthal@post.idc.ac.il

${ }^{\ddagger}$ Copenhagen Business School, email: pf.fi@cbs.dk

${ }^{\S}$ London Business School, CEPR; email: vvig@london.edu 


\section{Introduction}

The last decades have seen unprecedented waves of leveraged buyout (LBO) activity, identified by rating agencies as "a primary force behind the global rise in credit risk and the decline in credit quality" 1 In late 2015 Standard \& Poor's issued a warning regarding excessive leverage in the buyout market, while the Financial Times reported that "credit risks are rising to the fore as private equity groups seek to put a near-record $\$ 540 \mathrm{bn}$ cash pile to work, pushing leverage back to levels not seen since the boom of 2007" 2 Recent history, thus, clearly shows that although buyouts ebb and flow with the business cycle, LBO activity is a mounting concern for debt investors.

A leveraged buyout is an acquisition of a company using a significant amount of borrowed funds. It involves substitution of equity for debt and, typically, elimination of publicly-held stock. The post-LBO firm frequently has high leverage, and as a result, LBOs typically cause a dramatic change in the risk profile of the target firm. As we show, existing outstanding bonds experience significant losses when an LBO is announced. This, in turn, suggests that this risk should be priced in spreads, not only by LBO targets, but also by peers, susceptible to undergoing an LBO in the future. Our paper quantifies this ex-ante impact of LBO activity on bond credit spreads in general.

The ex-ante relationship between LBO risk and credit spreads is theoretically ambiguous. On one hand, as mentioned above, credit spreads increase around LBO announcements - due to the increase in financial leverage - and bond investors should account for this risk by requiring a higher credit spread ex-ante. We call this effect the "leverage effect". On the other hand, the threat of a future LBO may reduce agency costs by disciplining managers (Jensen and Meckling, 1976, Jensen, 1986 and Innes, 1990), an effect we call the "disciplining effect". The disciplining effect of LBOs can naturally be viewed as reducing credit spreads (Qiu and Yu, 2009 and Francis, Hasan, John, and Waisman, 2010), but may also lead to an increase in credit spreads if managers pursue more profitable but riskier projects, beneficial for equity holders but detrimental to bondholders (Roades and Rutz, 1982).

In addition to the theoretical ambiguity of the effects of LBOs on credit risk, empirically identifying

\footnotetext{
${ }^{1}$ See "The leveraging of America: recent leveraged buyouts drive credit risk higher as the market churns", S\&P RatingsDirect, August 6, 2007, "Moody's warns on LBO debt defaults", Financial Times, May 29, 2012 and "LBOs 31\% of defaults since financial crisis", Fitch Wire, May 28, 2014.

${ }^{2}$ 'Growth in leveraged deals prompt credit risk warning', Financial Times, November 4, 2015.
} 
a causal link between LBO risk and credit spreads is challenging. The identification challenge is exemplified in a notable paper on this topic by Crabbe (1991), in which the author attempts to estimate the impact on yields of including an event risk covenant protecting bondholders against an LBO ("Poison Put"). Specifically, Crabbe (1991) regresses a small set of corporate bond yield spreads (72 in number), at the end of 1989, on a dummy variable indicating whether the bond includes the event risk covenant. Crabbe interprets the negative dummy (-32bps) as the result of the leverage effect. In light of the limited data available 25 years ago, the documented correlation was useful in understanding LBO risk, but one concern is that firms issuing bonds with event risk covenants are different from those issuing bonds without such covenants, thus leading to an omitted variables bias. In particular, firms that face higher LBO risk are potentially also lower credit quality firms. While Crabbe attempts to control for credit quality using several proxies, one may question the quality of the control variables and their correct functional form. When we apply Crabbe's cross-sectional regression to a much larger sample of 41,181 bond yield observations over 13 years, we obtain monthly estimates that are volatile, ranging from -46 to 92 basis points, positive in 112 out of 159 months. It is difficult to rationalize positive estimates arising from a pure leverage effect.

Employing a different approach, Qiu and Yu (2009) and Francis et al. (2010) measure bond spread changes around laws enacted in 30 U.S. states between 1985-1991 raising the cost of takeovers and arguably decreasing the likelihood of an LBO. Admittedly, the potential effect of these laws was not limited to LBOs but also to other takeover events and, therefore, their results, although informative, have to be interpreted with caution in the context of LBO risk. Qiu and Yu (2009) find that bond spreads increase in the year the law is enacted while Francis et al. (2010) find that bond spreads decrease in the month around the first press announcement that is related to the expected passage of these laws. Besides the general challenge in defining the event date in studies of law changes, there is evidence suggesting that the laws did not have an impact on hostile takeover activity Comment and Schwert, 1995 and Cain, McKeon, and Solomon, 2016).

In light of these ambiguous and conflicting empirical results, this paper revisits the link between LBO risk and bond credit spreads using a more extensive dataset of LBOs, CDS spreads and corporate bond transactions from recent decades, as well as a new estimation approach 3 We provide comprehensive

\footnotetext{
${ }^{3}$ In his regressions, Crabbe (1991) uses 72 observations from December 1989, Qiu and Yu (2009) use 4,951 observations
} 
and robust evidence on an economically significant ex-ante effect of leveraged buyouts leading to wider bond credit spreads. We find the impact of LBO risk to be largest in recent years and in bond maturities of 10-20 years.

We begin by studying the reaction of target firm credit spreads to LBO announcements in the US during the years 2002-2015. We study the reaction in bond markets, differentiating between bonds protected by event risk covenants and those that are not, to control for takeover protection. We focus on the latter since they are most common and document an average abnormal negative reaction of $5.1 \%$ in prices of unprotected bonds, confirming results in earlier literature documenting significant bondholder losses $4^{4}$ We also document an increase in 5-year CDS spreads of $94.2 \mathrm{bps}$, on average, from 180 to 274 bps.

We then proceed to the main contribution of this paper, namely to quantify the ex-ante relation between LBO risk and bond credit spreads. First, we investigate intra-industry credit spread reactions around LBO announcements, based on the finding in Harford, Stanfield, and Zhang (2016) that an LBO announcement significantly increases the likelihood that an industry peer becomes an LBO target in the following year. We find a significant intra-industry average increase of $9.93 \%$ in the 5-year CDS spread around the announcement and an average abnormal decrease of $1.02 \%$ in the price of unprotected bonds, providing evidence that LBO risk has a sizeable influence on credit spreads ex-ante.

We investigate the impact of the disciplining effect by estimating the abnormal price change of protected bonds around intra-industry LBO announcements. Bonds carrying a "Protective Put" covenant are "put" back to the issuer upon an LBO and, therefore, should not be affected ex-ante by the threat of an LBO event leading to an increase in leverage. They will, however, be influenced by the disciplining effect of an LBO threat. Any reaction in a protected bond's yield can, therefore, be attributed to the latter. We find a small and statistically insignificant abnormal price reaction of $0.1 \%$ in protected bonds, suggesting that the disciplining effect is not of economically significant magnitude.

To sharpen our analysis further, we investigate a sample in which every firm has at least two bonds outstanding: one with an event risk covenant and one without. We include firm and time fixed effects in from 1976-1995 and Francis et al. (2010) use 1,857 observations from 1985-1991. We use 28,916 bond observations from 2002-2015 in our main regression.

${ }^{4}$ See for example Baran and King (2010), Billett, Jiang, and Lie (2010), Warga and Welch (1993), Crabbe (1991), Asquith and Wizmann (1990), and Marais, Schipper, and Smith (1989). 
a panel regression of yield spreads on a dummy indicating the inclusion of an event risk covenant along with controls. We, thus, estimate the effect of an event risk covenant by comparing, at the same time and for the same firm, the difference in yield between bonds with an event risk covenant and bonds without. This provides a much cleaner identification of the LBO effect, in particular the leverage effect, since the within-firm comparison allows us to control for firms' credit quality non-parametrically. It should be noted that this identification strategy also controls for other time-varying omitted variables, such as expectation of changes in firm leverage unrelated to LBOs. Since such leverage changes would affect spreads on both types of bonds, our identification strategy differences it out. Using this approach, the average impact of not including an event risk covenant during the period 2002-2015 is 20.7 basis points.

Having identified the leverage effect as the dominant one in the relation between LBO risk and credit spreads, we propose a general way of incorporating LBO risk into structural models and derive closed-form solutions for credit spreads in two cases, the Merton (1974) model and Collin-Dufresne and Goldstein (2001)'s stationary leverage model. In both, the firm issues a zero-coupon bond and defaults if its value is below the face value of debt at maturity. We model the leverage effect by assuming that there is a time-varying probability - governed by an underlying intensity - of the firm undergoing an $\mathrm{LBO}$, at which point there is a jump in the amount of debt issued by the target.

It is important for us to be able to distinctly interpret the implications of the model as risk of an impending LBO rather than other corporate events leading to a change in leverage 5 To be able to do so, we calibrate the model to two measurements in the data that are unique to LBO risk: the frequency of LBOs and the ex-post impact of LBOs on bond prices. Specifically, we use the overall number of LBOs divided by the total number of firms as an annual proxy for the unobserved LBO intensity, allowing us to estimate the parameters of this process. Furthermore, to estimate the jump size in the event of an LBO, we match model-implied bond price reactions to historical ones. Besides an increase in the level of debt arising from financial engineering, there may also be an increase in firm value due to operational improvements arising from a change in management or, in case of a management-led buyout, stronger incentives for existing management put into place. In this case, bond price changes around an LBO

\footnotetext{
${ }^{5}$ Examples of other corporate events leading to a change in leverage are mergers, share repurchases or steep losses due to a lawsuit.
} 
reflect the joint effect of a leverage increase and operational improvements, and since the structural models are calibrated to these price changes, the model-implied ex-ante effects will reflect the net effect of the two opposing factors.

The calibrated models allow us to investigate the impact of LBO risk over time and across bond maturities. The average contribution of LBO risk to 10-year credit spreads is $18-21 \mathrm{bps}$, consistent with the event risk covenant regression estimates. The impact on the 10-year credit spread of a typical BBB-rated firm ranges from around 11-14bps in the early eighties to around 25-30bps in the high LBO periods 2005-2007 and 2012-2014. To examine the impact of LBO risk on the term structure of credit spreads we study a typical firm in an average year and find the contribution to be only 0 -2bps at the one-year maturity, but increasing to $18-24 \mathrm{bps}$ at the 15 -year maturity. We, therefore, conclude that while LBO risk has little impact at very short maturities, it affects the slope of the term structure of credit spreads quite significantly.

Incorporation of LBO risk can further our understanding of the cross-sectional variation in credit spreads. Standard structural credit risk models suggest that only firm specific variables such as asset volatility and leverage determine spreads. In our model, LBO risk is an additional variable explaining credit spreads, but unlike the aforementioned variables, LBO risk is not firm-specific. It might therefore, in part, explain the finding in Collin-Dufresne, Goldstein, and Martin (2001) that a common residual factor unrelated to firm-specific variables is an important determinant of credit spreads.

The rest of this paper proceeds as follows. Section 2 details the CDS, bond, covenant, and LBO data. Section 3 studies the reaction of the target firm's bond prices and CDS spreads around LBO

announcements. Section 4 presents the empirical study of the ex-ante effect of LBO risk on credit spreads and Section 5 concludes.

\section{Data}

In our analysis we use credit spreads, both CDS premia and corporate bond yield spreads, along with data on bond covenants and LBO announcements. We focus on the U.S. market and use four main data sources: CDS quotes from Markit, corporate bond transaction prices from TRACE, bond covenant information from Mergent FISD, and LBO announcements from Thomson One Banker. The data 
sources are well-known and used in a large number of studies and below we provide a brief description of each.

\section{Credit default swaps}

Credit default swaps are the most common type of credit derivative and have been actively traded in financial markets since the early 2000s. According to a report by the Bank for International Settlements, the total notional amount outstanding of CDS contracts was $\$ 14.6$ trillion at the end of June 2015. CDS premia abstract from certain bond characteristics such as decaying maturity and covenants.

The CDS dataset includes daily quotes for a broad cross-section of firms over the years 2001-2015. To be consistent with the data on corporate bonds we restrict our sample period to 2002:07-2015:09. CDS data are provided by Markit, a comprehensive data source that assembles a network of over 30 industry-leading partners who contribute information across several thousand credits on a daily basis. Based on the contributed quotes, Markit creates a daily composite for each CDS contract and rigorous cleaning of the data helps to ensure that the composite price closely reflects transaction prices. We use

all CDS quotes written on U.S. corporate entities and denominated in U.S. dollars. We retain only CDS on senior unsecured debt, which constitute $92 \%$ of all contracts. We focus on contracts with Modified Restructuring (MR) or No Restructuring (XR) clauses as these are the most common in the US. The MR contract is used, with the exception of firms for which the XR contract is more frequently traded. We focus on the 5-year contract, which is the most liquid.

\section{Bond transaction prices}

Corporate bond transactions data are obtained from the Financial Industry Regulatory Authority's (FINRA) Trade Reporting and Compliance Engine (TRACE). Since July 1, 2002, all dealers have been required to report their secondary over-the-counter corporate bond transactions through TRACE. The data set start on July 1, 2002 and ends on September 30, 2015. We apply standard filters (Dick-Nielsen, 2009 and Dick-Nielsen, 2014) to clean the dataset for errors. The information on TRACE includes time of execution, price, yield, and volume. We merge this data with information on the issue and its covenants, as described in the following section, and exclude all convertible bonds, as these might be expected to react differently from non-convertibles. We use senior unsecured bonds only. We calculate a bond daily price as the average price of all transactions on that day. 


\section{Bond covenants}

We retrieve bond covenant information from The Mergent Fixed Income Securities Database (FISD). The FISD contains detailed issue-level information on over 140,000 corporate, US Agency, US Treasury and supranational debt securities, collected from bond prospectuses and issuers' SEC filings including 10-K, 8-K, registration forms, etc. For each issue, the FISD provides a variable indicating whether detailed covenant information is collected for that issue.

One covenant is directly related to LBOs, namely a put, which gives the bondholder the option to sell the issue back to the issuer in the event of a change of control in the firm, typically at $101 \%$ of par value. The covenant is denoted as "Change Control Put Provision" in FISD and we refer to it as an "event risk" covenant. Out of the $9.1 \%$ of bonds for which information about covenants is provided in FISD, $41.6 \%$ are reported to have an event risk covenant.

\section{LBO announcements}

Data on LBO announcements are retrieved from Thomson One Banker. A deal is classified as a Leveraged Buyout if the investor group includes management or the transaction is identified as such in the financial press and $100 \%$ of the company is acquired. We filter by announced deals of type LBO, where the target is a US firm 6 The total number of announcements between 1980 and 2015 is 12,210. Figure 1 details the number and total value of LBO announcements in the U.S. by year. The figure illustrates clear trends in buyout activity over time. We observe increased LBO activity in the late 1980s, in the 2004-2007 period preceding the financial crisis, and again in 2012-2015, both in number and magnitude of deals. $]^{7}$

\footnotetext{
${ }^{6}$ Based on the CapitalIQ database and World Economic Forum reports, the coverage of deals in Thomson One Banker seems to be incomplete, but there is no reason to suspect any bias in coverage. Furthermore, since LBO firms in our sample all have quoted CDS premia, the focus is, by definition, on the larger, public, frequently traded firms, for which the coverage is likely to be high. We checked LBOs on Bloomberg and did not find additional LBO events where the target firm had quoted CDS premia.

${ }^{7}$ The value is the equity value of target firms, but since only $16.2 \%$ of the deals in Thomson One Banker have this information, the reported value is a lower bound on the actual total value (although we expect that the $16.2 \%$ for which there is information are among the largest LBO deals).
} 


\section{Ex-post effect of LBO announcements}

In this section we study the effect of LBO announcements on the credit spreads of target firms. Before we examine the general effect in the sample, we zoom in on two specific deals: Heinz in 2013 and Safeway in 2014.

Berkshire Hathaway and 3G Capital announced on February 14, 2013 that they had reached an agreement with Heinz to take the company private in an LBO that valued the firm's equity at $\$ 23 \mathrm{bn}$. Before the LBO, total debt was $\$ 6.2 \mathrm{bn}$ and the firm's leverage ratio was $24.2 \%$. After the deal, $\$ 12.5 \mathrm{bn}$ of new debt was issued, senior to the existing debt. Thus, existing debt became significantly more risky and post-LBO Heinz had a leverage ratio of $49.9 \%$. The firm was subsequently downgraded by Moody's from investment grade rating BBB to speculative grade rating BB-. The figures in the top row of Figure 2 show the reaction in Heinz bonds and CDS. Consistent with the increased credit risk, the top-left plot shows that an unprotected bond maturing in 2032 experienced a price drop of about 15\%. The top middle plot, on the other hand, depicts the price of one of Heinz's "protected" bonds that had event risk covenants. As the graph shows, the bond did not suffer losses around the LBO announcement. Consistent with the drop in price of unprotected bonds, we observe in the top-right plot that the five-year CDS premium jumped from about 50 to $200 \mathrm{bps}$.

On February 19, 2014 Safeway announced that it was "in discussions concerning a possible transaction involving the sale of the company" and on March 6, 2014 it was announced that the private equity firm Cerberus Capital Management had agreed to buy Safeway in a leveraged buyout deal worth more than $\$ 9$ billion, of which $\$ 7.6$ billion would be in debt. A Safeway bond maturing in 2031 with no event risk protection lost approximately $10 \%$ in value in the period around the announcement, as the bottom-left plot of Figure 2 shows. On the other hand, the bottom-middle plot shows that the price of a protected bond maturing in 2020 did not decrease at all. Also, the bottom-right plot depicts a jump of approximately 100bps in the five-year CDS premium on Safeway bonds (from about 200 to 300bps).

While the above examples are illustrative of two specific cases, we now show the patterns observed in the bonds and CDS of Heinz and Safeway to be typical of LBO targets. In our study, we examine price reactions around LBO announcements in a large sample of LBOs. The event study methodology is detailed in Appendix A. We include only LBO announcements for firms which have CDS traded at 
some point in the sample period 2002:07-2015:09, leaving us with 117 firms. Since the focus is on firms with public debt and traded CDS contracts, the firms are typically large and publicly traded.

There are 60 LBO announcements for which we have 5-year CDS spreads around the event. The median rating is BBB- immediately before the announcement and BB- one year post the event. We exclude 18 cases where the 5-year CDS spread data are stale around the announcement 8 Panel A in Figure 3 shows that the CDS spread increases, on average, in the period leading up to the LBO announcement and, in particular, on the day of the announcement, remaining stable from that point onwards. It is not surprising that there is some reaction before the announcement, as the deal may have been rumored, or, as in the case of Safeway, the firm might have announced that negotiations were ongoing. On average, the CDS spread increases approximately 100 basis points from 180 to 280 basis points and Panel A in Table 1 shows the increase to be statistically significant.

Of the 117 firms which have CDS traded at some point in the sample period and experience an LBO, there are 45 firms with 230 bonds trading actively around the announcement 9 To investigate bond price reactions, we calculate the average abnormal price reaction of all these bonds and adjust the t-statistics to account for the correlation between bonds issued by the same firm (see Appendix A). Panel B in Table 1 shows that the average abnormal return is $-4.18 \%$ in the period between 22 days before and five days after the event and that this price drop is statistically significant. There are 187 unprotected bonds issued by 28 firms and Panels B in Figure 3 and C in Table 1 document a statistically significant cumulative abnormal return of $-5.05 \%$ around the event ${ }^{10}$ For bonds protected by an event risk covenant (43 such bonds issued by 21 firms), Panels B in Figure 3 and D in Table 1 show a small and statistically insignificant negative abnormal return of $0.40 \%$. Thus, although, on average, event risk covenants mitigate losses to bondholders, the majority of bonds are unprotected and bondholders experience significant losses.

Using a sample of bonds over the period 1991-2006, Billett et al. (2010) find that protected bonds experienced an average gain of $2.30 \%$ upon an LBO announcement, while unprotected bonds experienced an average loss of $6.76 \%$. A likely explanation for why we find (small and insignificant) average losses

\footnotetext{
${ }^{8}$ We define CDS prices as stale in the event window if there are more than five consecutive days in which the CDS price does not change.

${ }^{9}$ We define a bond as actively traded if there are no more than five days in the event window where there is no transaction. On days with no transaction we use the previous day's price.

${ }^{10}$ In "unprotected bonds" we include those that have no information about event risk covenants in the Mergent FISD.
} 
for protected bonds is that interest rate levels in our sample period were low and decreasing, thus a larger fraction of protected bonds were likely to be trading above the event put strike price of $\$ 101$, and, therefore, experienced some losses despite the event risk protection.

\section{Ex-ante pricing of LBO restructuring risk}

The event study in the previous section documents that, on average, bond prices decline after an LBO announcement, reflecting heightened credit risk. We attribute this increase in credit risk to the increase in leverage that typically accompanies an LBO and denote this as the "leverage effect", consistent with previous literature (Crabbe, 1991 and Qiu and Yu, 2009).

Since credit spreads are forward-looking, reflecting all priced risks, the leverage effect should lead to a positive ex-ante relation between LBO risk and credit spreads. However, an increase in LBO risk may also reduce agency costs as the more imminent takeover threat to managers makes them less likely to enjoy the "quiet life" (Bertrand and Mullainathan, 2003). This reduction in agency costs is generally seen as implying a negative relation between LBO risk and credit spreads (see for example Qiu and Yu, 2009 and Francis et al., 2010), but managers leading "the quiet life" may trade off higher profits for less risk, leading to a potential positive relation between LBO risk and credit spreads (Roades and Rutz, 1982). Therefore, the qualitative effect of the disciplining channel on credit spreads is unclear. In the following sections, we study the ex-ante relation between LBO risk and credit spreads, both estimating its magnitude and shedding light on the significance of the aforementioned opposing factors. We address the question at both the industry and firm level (Sections 4.1 and 4.2, respectively), as well as across bond maturities and over a time period of over three decades (Section 4.3).

\subsection{Industry-wide effects of LBO announcements}

We start by examining the existence of intra-industry LBO risk "contagion". This study is based on widely documented industry-level clustering of LBO activity over time, as shown in Figure 4. The figure displays the percentage of LBOs occurring in different industries out of the total number of LBOs by decade and shows industries for which the percentage was over $3 \%$ in at least one decade. The composition of LBO-intensive industries has clearly changed over time. In the early buyout wave (1980- 
1989), most LBOs occurred in Industrial Machinery and Equipment, in Metal and Paper Products, in particular. Strikingly, there is an increase in LBO activity in Business Services from 3.4\% in 1980-1989 to $19.0 \%$ in 2010-2015, out of which Computer and Data Processing Services account for 1.5\% and $13.3 \%$ respectively.

Consistent with this industry-level clustering, Harford et al. (2016) document that an LBO announced in a given year significantly increases the likelihood that an industry peer becomes an LBO target the following year. To investigate their finding in our sample we estimate a panel regression in Table 2 where we regress the number of LBOs in an industry on the number of LBOs in the same industry the period before. The results confirm the findings of Harford et al. (2016). For example, when the time period is one year, the slope coefficient when including time and industry fixed effects is statistically highly significant at 0.86 and the $R^{2}$ is 0.85 . These results imply that an LBO announcement increases the likelihood that other firms in the industry will also be subsequently targeted in LBOs, suggesting that intra-industry reactions to LBOs are informative regarding the relation between LBO risk and credit spreads.

To study this question, we use the same set of LBO events as in the previous section, namely LBO announcements of 117 firms for which we have CDS spreads at some point in the sample period 2002:072015:09. For each LBO event, the sample consists of spreads of non-targets in the same industry in a window around the announcement. We match 2-digit SIC codes from Compustat using Markit tickers. Event window, abnormal returns and test statistics are as detailed in Appendix A.

Figure 5 Panel A shows increasing CDS premia on the two days around the announcement and subsequent increasing premia in the three weeks following the announcement. Table 3 Panel A shows that the increases both around and after the announcement are statistically significant: the average cumulative abnormal return is $9.93 \%$ in a 27 -day interval around the event, displaying a significant within-industry reaction to LBO announcements.

The perceived increase in the probability of an LBO can affect spreads through two channels. One channel is the leverage effect, through which an increase in financial leverage around the LBO leads to an increase in credit spreads. Another channel is the disciplining effect, whereby a takeover is a more imminent threat to managers, reducing agency costs. While the reaction of CDS spreads does not allow 
us to investigate the channels separately, we can use bond price reactions to shed light on the relative significance of the two.

Corporate bonds without an event risk covenant are exposed to both channels and we would, therefore, expect their spreads to react in the same way as CDS premia. This is indeed the case as Table 3 Panel C and Figure 5 Panel B show: the average abnormal price reaction of unprotected bonds is $-1.02 \%$. In contrast, we expect corporate bonds with an event risk covenant to react differently. Protected bondholders are affected by an intra-industry LBO announcement through the disciplining of management. However, in case of the issuing firm being the target of an LBO at a later date, protected bondholders essentially sell the bond back at par, and are, therefore, not concerned about any future LBO-induced leverage increase. In turn, this implies that protected bonds are exposed to the disciplining channel but not the leverage one.

Panel B in Figure 5 shows that the price reaction of protected bonds around intra-industry LBO announcements is small. Table 3 Panel $\mathrm{D}$ shows the average cumulative abnormal return in 27 days around announcements to be only $0.10 \%$ and statistically insignificant. Thus, the disciplining effect of LBOs appears to be small and insignificant relative to the leverage effect.

There are other explanations consistent with the widening of intra-industry CDS spreads and the drop in unprotected bond prices around LBO announcements. Mitchell and Mulherin (1996) find that intra-industry buyout patterns are related to industry-wide economic shocks; an LBO in one firm might provide relevant economic information about other firms within the same industry, causing a subsequent change in their pricing. Harford et al. (2016) find that LBOs cause or signal private information about optimal changes in the industry and lead to a range of changes in the target's peers, such as changes in investment outlays, strategic alliances, and anti-takeover provisions. It may also be the case that some firms "mimick" an LBO and increase leverage in the future.

While it is clear that LBOs may be informative in different ways, there are two reasons why we find it unlikely that the change in spreads around LBOs is due to the alternative explanations. Table 3 Panel $\mathrm{E}$ and Figure 5 Panel $\mathrm{C}$ show that there is a positive and significant abnormal equity price reaction of the target's peers around the announcement. If the increase in spreads is due to a downward repricing of firms, we would see a widening of credit spreads along with negative equity returns. Furthermore, 
while protected bonds are not exposed to the leverage channel, their prices are not protected against repricing caused by the above alternatives and we would expect to see a similar price reaction for both protected and unprotected bonds. For example, bonds with an event risk covenant are protected against LBOs but not against future increases in leverage that are not associated with ownership change.

Anecdotal evidence from the press further supports the hypothesis that the increase in CDS spreads is mainly driven by increased probability of further LBOs. Bloomberg Business ("Dell Lifts Default Risk on Next Buyout Targets: Credit Markets") wrote in January, 2013 that "Derivatives traders are beginning to speculate that the potential leveraged buyout of computer maker Dell Inc. marks the return of credit-busting takeovers as the cost of financing the deals gets ever cheaper. The cost to protect against losses on Quest Diagnostics Inc. bonds reached a 15-month high yesterday and Nabors Industries Ltd. credit-default swaps jumped to the most since July amid speculation they may become targets for leveraged buyouts." The Wall Street Journal also wrote on February 3, 2013 ("New Worry for Bondholders: LBOs") that "bonds from other likely LBO targets [...] have fallen in value. Leader Capital Corp. portfolio manager Scott Carmack noticed unusual selling in bonds of telecommunications provider CenturyLink Inc. and Nabors when talk of the Dell deal leaked."

Overall, we find that LBO risk causes an increase in within-industry credit spreads, operating primarily through a leverage channel, while the disciplining effect of LBOs appears small. In the next sections we attempt to quantify the total impact of LBO risk on credit spreads.

\subsection{Corporate bonds and event risk covenants}

Recent years have seen a significant increase in the percentage of bonds issued with event risk covenants, as can be seen in Figure 6. The percentage of first-time issuers issuing bonds with event risk covenants has risen steadily from $0 \%$ in the early eighties (prior to the buyout wave of the late 1980s) to $80 \%$ at the end of our sample (end of 2015) ${ }^{11}$ The figure shows a similar trend for firms that already had both a protected and non-protected bond outstanding at time of issuance. The increasing use of event risk covenants suggests that it has become common to have both protected and unprotected bonds outstanding: out of 511 (297) firms that issued a bond in 2015, where the issuer had at least two

\footnotetext{
${ }^{11}$ In the figure 'Have no bonds outstanding' corresponds to the firm having no previous bonds outstanding for which we have event risk information. If we instead condition on the firm having no bonds outstanding, whether we have event risk covenant information on the bonds or not, the time series correlation is $97 \%$ with the series in the figure.
} 
(five) bonds outstanding, $26.2 \%(38.3 \%)$ had both types of bonds.

A plausible explanation for the increasing use of covenant protection is investor demand. Anecdotal press reports support this explanation. For example, Reuters writes on February 22, 2013, under the headline "Investors demand LBO protection in US bonds", that "there have been deals recently where large investors have decided to walk away, or threatened to do so, if there was no change of control put included in the structure." Financial Times writes on March 22, 2006, under the headline "Bondholders seek protection from LBOs", that "BAA, the UK airport operator, was in the process of completing a 2bn bond issue when Ferrovial, the Spanish infrastructure group, shocked the market by announcing it was considering a takeover bid. Investors, who had been happy to buy the bonds without any specific protection, revolted and forced BAA to change the terms. Because the deal had yet to be formally completed, investors threatened to walk away from it."

Billett et al. (2010) find that the probability of being an LBO target is reduced if the target firm has at least one bond with an event risk covenant outstanding. If this is also the case in our more recent sample period, the effect of LBO risk on pricing is stronger for firms with no protected bonds outstanding relative to firms with at least one protected bond outstanding. Since we restrict our sample in the following analysis to firms with at least one protected bond outstanding, we can interpret our results as a lower bound.

As evidenced earlier, bonds with an event risk covenant react differently to an LBO announcement than bonds without an event risk covenant. Bonds with an event risk covenant are "put" back if the issuer is the target of an LBO and, therefore, these bonds are not exposed to the direct effect of increased leverage upon the LBO. Protected bonds are, however, possibly affected indirectly because the threat of an LBO may reduce agency costs. We document in the previous section that there is no material price reaction of protected bonds to an increase in LBO probability - suggesting that agency costs play a minor role in bond valuation - and we, therefore, focus on the leverage channel. Unsecured bonds remain in the capital structure of a target firm after an LBO and the risk of an LBO-induced increase in financial leverage should affect valuation of unprotected bonds ex-ante. Consequently, we estimate the effect of the leverage channel by comparing credit spreads of bonds with and without event risk covenants. 
Crabbe (1991) uses a similar approach to isolate the impact of the leverage effect on credit spreads. Specifically, Crabbe regresses the 1989 year-end yield spread of 72 bonds on a dummy indicator for event risk, controlling for credit risk, maturity and liquidity (using rating dummies, maturity and size, respectively). The regression coefficient on the event risk dummy in Crabbe's regression is -32bps, indicating that the average effect of LBO risk on credit spreads via the leverage channel at the end of 1989 was 32 basis points. Using the same cross-sectional regression in the first six months in 1990 Crabbe finds that the effect of LBO risk decreased to around 15bps by June 1990.

Including covenants in a bond issue is an endogenous decision by the issuing firm. Consistent with Smith and Warner (1979)'s Agency Theory of Covenants, Bradley and Roberts (2015) find that riskier firms are more likely to issue loans with covenants and Billett, King, and Mauer (2007) find that covenant protection in public bonds is increasing in growth opportunities and leverage. This poses a challenge when using event risk covenants to assess the pricing impact of LBO risk through the leverage channel.

To examine the approach in Crabbe (1991) more closely, we estimate the same cross-sectional regression on a monthly basis over the period 2002-2015, resulting in 159 cross-sectional regressions. In each month, we use the last transaction in the month to calculate a bond's yield and discard the bond if there are no transactions in the month. Table 4 reports the distribution of the 159 regression coefficients. The average number of observations in the monthly regressions is 259, compared to Crabbe's 72 observations, and we estimate the regression in 159 months while Crabbe restricts his analysis to 7 months. The average regression coefficient on the event risk dummy in our analysis is 8.59, suggesting that adding an event risk dummy increases credit spreads by 8.59 basis points, on average. The coefficient is positive in 112 out of 159 regressions, i.e. in over $70 \%$ of the months. A positive relation between an event risk covenant and credit spreads is difficult to interpret, intensifying concerns about covenants being an endogenous firm decision.

To assess the pricing impact of LBO risk using event risk covenants, we propose a different approach that directly controls for the simultaneity between pricing and the inclusion of an event risk covenant. In our analysis, we restrict our sample to firms that have at least two bonds outstanding, where at least one was issued with an event risk covenant, and at least one was issued without. We estimate the impact of an event risk covenant as the difference in yields on a bond with an event risk covenant and 
a bond without, where the yields are as of the same time and the bonds were issued by the same firm. The latter controls for factors known to affect credit spreads, such as leverage and volatility. We run the analysis in a panel regression, using firm (interacted with time) fixed effects.

As in Crabbe (1991) we restrict our sample to senior unsecured bonds issued by industrial firms, with a remaining maturity of at least seven years, an investment grade rating (BBB- or higher) and a fixed coupon. We further exclude bonds that are puttable, convertible, asset-backed and non-USD denominated. Also, since the vast majority of bonds with event risk covenants are callable, we exclude non-callable bonds to avoid the confounding effect of callabillity.

In each month in the sample period 2002-2015, we include all bond observations from firms which have at least one bond outstanding with an event risk covenant and at least one bond outstanding without an event risk covenant (we use the last transaction in the month to calculate a bond's yield and discard the bond if there are no transactions in the month).

Table 5 shows summary statistics for our sample of bonds. We see that the average maturity of protected bonds is 17.09 years, slightly lower than that of unprotected bonds - 18.39 years. Feldhütter and Schaefer (2018) find the average investment grade spread for U.S. bonds for the period 1987-2012 to be very similar for short-, medium-, and long-maturity bonds, making it less likely that a potential maturity mismatch would have a material effect, but nevertheless we will control for bond maturity in several ways. Table 5 also shows that protected bond issues are generally larger (average log amount outstanding is 13.15 for protected bonds vs 12.08 for unprotected bonds) and their liquidity is higher as measured through the commonly used Amihud and Roll illiquidity measures where higher value implies lower liquidity (see Bao, Pan, and Wang, 2011, Dick-Nielsen, Feldhütter, and Lando, 2012, Friewald, Jankowitsch, and Subrahmanyam, 2012, and others) ${ }^{12}$ Bond illiquidity is known to affect corporate bond prices and can influence our results, so we will be careful to control for illiquidity. (Dick-Nielsen et al. (2012) and Feldhütter and Schaefer (2018) find that the impact of bond illiquidity on corporate bond prices is small for investment grade bonds, suggesting bond illiquidity is less likely to have a material impact in our sample.) Finally, we see that protected bonds, on average, also include $17.6 \%$ of other covenants as appear in Mergent FISD (excluding the event risk one), while unprotected bonds

\footnotetext{
${ }^{12}$ We calculate the Amihud and Roll measures for a given bond on a monthly basis using all transactions within a month and follow the methodology in Dick-Nielsen et al. (2012).
} 
include $11.0 \%$ of other covenants. We, therefore, include other covenants as regression controls, as well.

We analyze event risk covenants in a panel regression with time $\times$ firm fixed effects. Specifically, we estimate the panel regression

$$
s_{i j t}=\alpha_{i t}+\beta 1_{\{j \in E R C\}}+\gamma_{1} x_{j}+\gamma_{2} x_{j t}+\epsilon_{i j t},
$$

where $s_{i j t}$ is the credit spread in month $t$ of bond $j$ issued by firm $i, \alpha_{i t}$ are firm interacted with month fixed effects, $1_{\{j \in E R C\}}$ is an indicator that is one if bond $j$ includes an event risk covenant, $x_{j}$ includes the time invariant controls 'other covenants' and 'log amount outstanding', while $x_{j t}$ includes the time-varying controls 'maturity', 'maturity2', 'Amihud', and 'Roll'. The fixed effects account for the time-varying credit risk of firms, and therefore (abstracting from the influence of controls) the regression coefficient $\beta$ corresponds to the average effect on spreads of including an event risk covenant.

Table 6 specification 1 shows that without any controls, the effect of including an event risk covenant is estimated to lower the yield spread by 25.04 basis points, on average. The next specification shows that other covenants and bond size have an insignificant impact, while specifications 3 and 4 show that controlling for maturity is important and results are similar whether the maturity control is linear or non-linear. Once we control for other covenants, bond size and bond maturity, the estimated effect of including an event risk covenant is 20.66 basis points, still economically and statistically highly significant. Specifications 5-7 control also for bond liquidity, which is shown to be insignificant in the yield difference between protected and unprotected bonds. Overall, we find the average impact of protecting a bond from a change in control to be 20.7 basis points and, thus, that is our estimate for the average impact of LBO risk (where a change in control occurs) on medium to long-term credit spreads.

Table 6 shows a negative coefficient ranging from -13.11 to -10.37 on other covenants. A negative coefficient is in line with the argument that including more covenants places additional restrictions on management and proves beneficial to bondholders. It may be surprising that the estimated coefficient is economically modest and statistically insignificant (going from no other covenants to the complete menu of other covenants only reduces the yield spread by 10.37-13.11 basis points). This does not necessarily imply that other covenants do not have a notable impact on the cost of debt. Instead, the benefits of most of these other covenants accrue to all bond issues once they are included in at least one, as discussed in Helwege, Huang, and Wang (2016). Therefore, the effect of other covenants is most 
likely absorbed by the firm fixed effect, in contrast to the event risk covenant, which is bond-specific.

As mentioned, following Crabbe (1991) we exclude bonds with a maturity of less than seven years. If we include bonds with a maturity of at least 0,3 , or 5 years, the regression coefficient on the event risk covenant in Table 6 specification 4 is $-10.7,-14.9$, and -18.0 basis points, respectively. Thus, the effect is smaller for short-maturity bonds and we explore this maturity effect further in a structural model in the next section 13

To examine the time series variation in the impact of LBO risk, we run regression (1) for each month separately ${ }^{14}$ Panel A in Figure 7 shows the time series of the estimated contribution of LBO risk to credit spreads. The figure displays the negative value of the regression coefficient on the event risk dummy, so a positive value in the plot represents a positive contribution of LBO risk to spreads (based on a negative regression coefficient). We begin the analysis in 2007 because all preceding months have fewer than 20 firms in the sample and result in noisy estimates. For comparison, Panel B shows the estimated contribution using the method in Crabbe (1991). According to our estimates, the impact of LBO risk was low after the 2008 financial crisis, but has increased in the past years, consistent with heightened LBO activity. In contrast, Crabbe's methodology frequently gives rise to negative estimates.

Overall, we find that LBO risk has an economically and statistically significant ex-ante impact on spreads, of $20.7 \mathrm{bps}$, on average. In the next section we further study the variation of this impact both in the time series, over the period 1980-2014, and across the term structure of bond maturities.

\subsection{Evidence from structural models with LBO risk}

In the previous sections we document that LBO risk has a significant ex-ante impact on credit spreads. Our results also suggest this link is largely due to the typical increase in financial leverage upon an LBO. Based on these results, in this section we present a framework for studying LBO risk in structural models of credit risk.

Specifically, we extend standard structural models by incorporating the leverage effect: there is a time-varying probability of the firm undergoing an LBO and, if an LBO occurs, the firm's leverage is

\footnotetext{
${ }^{13}$ This provides formal evidence for the informal argument Crabbe gives for excluding short-maturity bonds in his footnote 6: "corporate notes with short maturities, which are frequently issued as part of swap transactions, are not so likely as long-term bonds to suffer large price declines as a result of the realization of event risk."

${ }^{14}$ Specifically, we run repeated monthly regressions corresponding to Table 6 specification 4.
} 
increased. We implement the framework in the classic Merton (1974) model and in the Collin-Dufresne and Goldstein (2001) model with stationary leverage and calibrate the models to present further evidence on the pricing of LBO risk over time and across bond maturities.

\subsubsection{The Merton model with LBO risk}

Assume that firm value follows a Geometric Brownian Motion

$$
\frac{d V_{t}}{V_{t}}=(r-\delta) d t+\sigma d W_{t}^{V}
$$

under the risk neutral measure, and $r$ is the riskfree rate while $\delta$ is the total payout to debt and equity holders 15 Assume that the firm has issued one zero-coupon bond with maturity $T$ and a face value of K. The firm can only default at bond maturity and it does so if firm value is below the face value of debt. Following Chen, Collin-Dufresne, and Goldstein (2009) and Feldhütter and Schaefer (2018) we assume that in the event of default, bondholders receive a fraction $\alpha$ of the face value of debt. If we define leverage as $L_{t}=\frac{K}{V_{t}}$ and the price of the zero coupon bond at time 0 as $v^{M}\left(L_{0}, \delta, \sigma, \alpha, r\right)$ it is well-known that

$$
v^{M}\left(L_{0}, \delta, \sigma, \alpha, r\right)=e^{-r T}\left[\alpha+(1-\alpha) N\left(\frac{-\log \left(L_{0}\right)+\left(r-\delta-\frac{1}{2} \sigma^{2}\right) T}{\sqrt{\sigma^{2} T}}\right)\right] .
$$

We extend the model by assuming that the firm can potentially undergo an LBO at time $\tau$. if an LBO occurs, the firm issues more debt with the same maturity and seniority as existing debt. The total amount of debt after the LBO is $e^{J} K$ where $J$ is normally distributed with mean $\eta$ and standard deviation $\varsigma{ }_{16}^{16}$ We assume that the LBO event follows a Cox process with intensity $\lambda_{t}$ (see Lando, 1998). This implies that in a short time interval between $t$ and $t+\Delta$, the probability of an LBO occuring is approximately $\lambda_{t} \Delta$. We assume that $\lambda_{t}$ follows a CIR process,

$$
d \lambda_{t}=\kappa\left(\theta-\lambda_{t}\right) d t+\xi \sqrt{\lambda_{t}} d W_{t}^{\lambda}
$$

and that $W^{\lambda}$ and $W^{V}$ are independent. Appendix $\mathrm{B}$ shows that the probability of an LBO event not occurring during the life of the bond is

$$
P\left(\lambda_{0}, \kappa, \theta, \xi\right)=E\left[e^{-\int_{0}^{T} \lambda_{s} d s}\right]=A(T) e^{-B(T) \lambda_{0}}
$$

\footnotetext{
${ }^{15}$ See Feldhütter and Schaefer $\left.\sqrt{2018}\right)$ for a more extensive discussion of the assumptions of the model.

${ }^{16}$ It can happen that the firm retires debt if $J<0$. If this happens we assume that the firm buys back debt at post-LBO market value.
} 
where

$$
\begin{aligned}
A(T) & =\left(\frac{2 h e^{(h+\kappa) T / 2}}{2 h+(h+\kappa)\left(e^{h T}-1\right)}\right)^{\frac{2 \kappa \theta}{\xi^{2}}} \\
B(T) & =\frac{2\left(e^{h T}-1\right)}{2 h+(h+\kappa)\left(e^{h T}-1\right)} \\
h & =\sqrt{\kappa^{2}+2 \xi^{2}} .
\end{aligned}
$$

The price of the zero coupon bond in the presence of LBO risk is derived in Appendix B as

$$
\begin{aligned}
& v_{T}^{L B O}\left(L_{0}, \delta, \sigma, \alpha, r, \lambda_{0}, \kappa, \theta, \xi, \eta, \varsigma\right) \\
& \quad=P\left(\lambda_{0}, \kappa, \theta, \xi\right) v^{M}\left(L_{0}, \delta, \sigma, \alpha, r\right)+\left[1-P\left(\lambda_{0}, \kappa, \theta, \xi\right)\right] v^{M}\left(L_{0}, \delta+\frac{\eta}{T}-\frac{1}{2} \frac{\varsigma^{2}}{T}, \sigma^{2}+\frac{\varsigma^{2}}{T}, \alpha, r\right)
\end{aligned}
$$

The pricing formula shows that the bond price is a weighted average of the bond price in the standard Merton model and the bond price in the standard Merton model with an adjusted drift and volatility, where the weight is the probability of an LBO occurring during the life of the bond. The adjusted volatility is higher, and for empirically plausible parameters the drift is adjusted downwards.

We estimate the LBO risk parameters of the structural models assuming that there is no risk premium associated with LBO events. Parameters associated with LBO intensity are estimated using the time series variation in the market-wide frequency of LBOs. The parameters determining the increase in leverage when an LBO happens are estimated by matching model-implied bond price reactions to an LBO to historical bond price reactions around LBOs.

We estimate the time variation in contribution to spreads of LBO risk for a "typical" firm issuing corporate bonds. The most common ratings in the corporate bond market are A and BBB. The average leverage ratios of A and BBB-rated firms are estimated in Feldhütter and Schaefer (2018) [FS18] to be 0.28 and 0.38 , respectively. The median pre-event rating of firms subject to an LBO is BBB and the average leverage in the year before the LBO is 0.33 in our sample. We therefore choose 0.33 as leverage. The asset volatilities of $\mathrm{A}$ and BBB-rated firms are 0.23 and 0.25 , respectively (FS18), so we choose the average of 0.24 as asset volatility. The drift of the assets under the risk neutral measure is $r-\delta$, where $r$ is the riskfree rate and $\delta$ is the payout rate to debt and equity holders (as a percentage of firm value). We set $r$ equal to the average 5-year Treasury yield for the period $1980-2014$ of $6.10 \%$ and the payout ratio to $4.85 \%$ (the average payout rate of $\mathrm{A}$ and $\mathrm{BBB}$ firms according to FS18) 17 Finally, we

\footnotetext{
${ }^{17}$ Feldhütter and Lando (2008) show that the swap rate is a better proxy for the riskfree rate than the Treasury yield, but swap rates are not available before 1987.
} 
set the recovery rate $\alpha=37.8 \%$, Moody's (2013)'s average recovery rate for senior unsecured bonds for $1982-2012$.

We calculate a market-wide annual LBO probability by computing the ratio of the number of public firms that were targets of an LBO (according to Thomson Financial LBO announcements) to the total number of firms (as reported in Compustat). Both the denominator and numerator reflect public firms, so the probability reflects that of listed companies. We let the time series of LBO probabilities proxy for the path of $\lambda$, observed on a yearly basis. The average annual LBO probability in the period 1980-2014 is $1.83 \%$. We estimate the parameters $\kappa, \theta$, and $\xi$ in equation (4) by Maximum Likelihood using the method in Kladıvko (2007); they are estimated to be $\kappa=0.1946, \theta=0.0215$ and $\xi=0.0511$. A mean reversion of $\kappa=0.1946$ implies that the half-life of a shock to the LBO intensity is $\frac{\log (2)}{0.1946}=3.56$ years, consistent with LBO intensity varying with the business cycle. $\theta$ is close to the unconditional mean of 0.0183 .

As noted previously, if there is an LBO, total debt jumps from $K$ to $K e^{J}$ where $J \sim N(\eta, \varsigma)$. $\varsigma$ is hard to identify and we, therefore, set this parameter to $\varsigma=0.2$ (other values give rise to similar results). The average jump in log-leverage, $\eta$, is crucial and we back out the parameter by fitting model-implied price reactions to historical price reactions around an LBO. We do this for different bond maturities. We use bond price reactions in the period 2002-2015 to the LBO announcements of 117 firms described in Section 3 and the average historical price reactions are given in Table 7 Panel A. We denote the historical price reaction at bond maturity $t_{i}$ by $\operatorname{pre}^{\text {hist }}\left(t_{i}\right)$ (we assume that $t_{i}$ is the mid-point in a given maturity range, such that for example the range 8-10 years corresponds to $t_{i}=9$ ). For a given bond maturity $t_{i}$, the corresponding model-implied price reaction in the Merton model is calculated as

$$
\operatorname{pre}\left(\eta, t_{i}\right):=\frac{v_{t_{i}}^{M}\left(e^{\eta} L_{0}, \delta, \sigma, \alpha, r\right)-v_{t_{i}}^{L B O}\left(L_{0}, \delta, \sigma, \alpha, r, \lambda_{0}, \kappa, \theta, \xi, \eta, \varsigma\right)}{v_{t_{i}}^{L B O}\left(L_{0}, \delta, \sigma, \alpha, r, \lambda_{0}, \kappa, \theta, \xi, \eta, \varsigma\right)}
$$

where $v_{t_{i}}^{M}$ is as given in equation (3) and $v_{t_{i}}^{L B O}$ is as given in equation (9) 18 The intuition for this is that before an LBO, the price is given as $v_{t_{i}}^{L B O}$ while after an LBO, log-leverage increases by $\eta$, on average, and the post-LBO price is given by the standard Merton model, as the firm can be an LBO target only once. The remaining parameters in (10) are set as above and $\eta$ is estimated by minimizing

\footnotetext{
${ }^{18}$ Although the expected jump in log-leverage is $\eta$, jumps are normally distributed around the mean. An alternative estimation approach to estimating $\operatorname{pre}\left(\eta, t_{i}\right)$ is to simulate the jumps $J$ and calculate the average price reaction. Since there is a close to linear relation between the bond price and the leverage jump size, the difference between the two approaches is small and we, therefore, use the simpler approach.
} 
the squared errors between model-implied and historical price reactions,

$$
\min _{\eta} \sum_{i=1}^{7}\left(\operatorname{pre}\left(\eta, t_{i}\right)-p r e^{h i s t}\left(t_{i}\right)\right)^{2}
$$

where 7 refers to the number of price reactions in Table 7 Panel A. The mean jump size is estimated to be $\eta=0.4216$.

Table 7 Panel A shows how well the Merton model captures the reaction for different maturities, although we have to be careful not to over-interpret the fit, as the standard errors on the historical price reactions are considerable. There is a hump-shaped relation between bond maturity and price reaction in the data: the price reaction is stronger for longer maturities until 10-20 years, whereafter the reaction becomes smaller. The price reaction in the model is stronger than in the data for maturities less than five years and weaker at maturities longer than 10 years, while at the 10-year maturity the reaction in the data and model are similar. Interestingly, the model captures the hump-shape in the price reactions with a steeply increasing reaction at short maturities, peaking at 8-20 years, and a decreasing percentage price reaction at longer maturities.

With the estimated LBO risk parameters and the time variation in the LBO intensity $\lambda$, proxied by the yearly LBO probability, we calculate on a yearly basis the model-implied credit spread for a typical firm both with and without LBO risk. Specifically, we compute the difference between the yield based on the bond price in equation (9) and the yield based on the price in equation (3). This difference in yields is the contribution of LBO risk. Figure 8 shows the contribution of LBO risk to the 10-year credit spread. We see that the contribution measures around 16-20bps in normal times and rises to 20-30bps before the recessions in 1990, 2001, and 2008.

Panel B in Table 7 shows that the contribution of LBO risk to credit spreads is hump-shaped as a function of maturity. We see that the contribution of LBO risk increases from $1.8 \mathrm{bps}$ at the one-year maturity to 17.6 bps at the 10-year maturity and then declines to 14.8 bps at the 30-year maturity. Intuitively, LBO risk is not as significant for short-maturity bonds, because although leverage jumps in an LBO, the firm is unlikely to be on the verge of default shortly after the LBO event.

When analyzing LBO risk by investigating bonds with and without event risk covenants, we found the average contribution to spreads in 2002-2015 to be 20.7 bps. To compare this result with the results implied by the structural model, we first note that the average bond maturity in the event risk covenant 
regression in Table 6 is 17.7 years. When we calculate the LBO contribution for a bond with a maturity of 17.7 years in the years 2002-2014 as in Table 7 Panel B (in this case the LBO intensity $\lambda$ is set to the average LBO probability in 2002-2014, 2.28\%), the average model-implied contribution is 18.3 basis points. Thus, the two different approaches give rise to similar estimates of the average contribution of LBO risk.

\subsubsection{Stationary leverage ratios}

Collin-Dufresne and Goldstein (2001) incorporate a stationary leverage ratio in a standard structural model. As Flannery, Nikolova, and Oztekin (2012) find further empirical support for this model, we consider stationary leverage ratios in the context of LBO risk. The effect of LBO risk is distinct from a stationary leverage ratio. In particular, changes in debt due to a stationary leverage ratio are predictable and slow-moving, while changes in debt due to LBO risk are unpredictable and large. To show that LBO risk is significant in debt pricing under a range of model assumptions, we incorporate LBO risk in Collin-Dufresne and Goldstein (2001)'s stationary leverage model and estimate the impact of LBO risk in the case of a stationary leverage ratio.

Assume that firm value follows a Geometric Brownian Motion

$$
\frac{d V_{t}}{V_{t}}=(r-\delta) d t+\sigma d W_{t}^{V}
$$

under the risk neutral measure and $r$ is the riskfree rate while $\delta$ is the total payout to debt and equity holders. Define $y_{t}=\log \left(Y_{t}\right)$ and assume as in Collin-Dufresne and Goldstein (2001) that the firm targets a long-run leverage ratio and that the dynamics of the log of the amount of debt, $k_{t}$, are given by

$$
d k_{t}=\phi\left(\nu-\left(k_{t}-y_{t}\right)\right) d t
$$

If we define log-leverage as $l_{t}=k_{t}-y_{t}$, the intuition is that if $l_{t}$ is less than $\nu$, the firm increases the amount of debt and vice versa, i.e. log-leverage is stationary around a mean leverage of $\nu$. This specification captures the idea that the firm tends to issue more debt when leverage is low and tends to retire debt when leverage is high. We assume that all debt has equal priority and matures at time $T$, i.e. if the firm issues more debt, it issues more debt with the same maturity and seniority as existing debt. The firm can only default at bond maturity $T$ and it does so if firm value is below the face value of all debt $K_{T}$. If the firm defaults, bondholders receive a fraction $\alpha$ of the face value of debt. 
As in Section 4.3 , we assume that the firm can potentially undergo an LBO that occurs at time $\tau$, in which case the firm issues more debt (with the same maturity and seniority as existing debt). To capture that leverage jumps after the LBO and that the target leverage is higher after an LBO, we assume that the total amount of debt immediately after the LBO is $K_{\tau} e^{J}$ where $J$ is normally distributed with mean $\eta$ and standard deviation $\varsigma$, while the target log-leverage after the LBO changes from $\nu$ to $\nu+J$. As in Section 4.3 we assume that the LBO event follows a Cox process with intensity $\lambda_{t}$ where $\lambda_{t}$ follows a CIR process,

$$
d \lambda_{t}=\kappa\left(\theta-\lambda_{t}\right) d t+\xi \sqrt{\lambda_{t}} d W_{t}^{\lambda}
$$

and that there is no risk premium associated with LBO risk.

Appendix $\mathrm{B}$ shows that the bond price is given as

$$
P\left(\lambda_{0}, \kappa, \theta, \xi\right) N\left(\frac{\bar{l}+\left(l_{0}-\bar{l}\right) e^{-\phi T}}{\sqrt{\frac{\sigma^{2}}{2 \phi}\left(1-e^{-2 \phi T}\right)}}\right)+\left[1-P\left(\lambda_{0}, \kappa, \theta, \xi\right)\right] N\left(\frac{\bar{l}+\left(l_{0}-\bar{l}\right) e^{-\phi T}+\eta}{\sqrt{\frac{\sigma^{2}}{2 \phi}\left(1-e^{-2 \phi T}\right)+\varsigma^{2}}}\right)
$$

where

$$
\bar{l}=\frac{-r+\delta+\frac{1}{2} \sigma^{2}}{\phi}+\nu
$$

and $P\left(\lambda_{0}, \kappa, \theta, \xi\right)$ is given in equations (5)-(8).

To disentangle the effect of LBO risk from that of a stationary leverage ratio, we calculate the spread in the model with and without LBO risk and compute the difference. We use Collin-Dufresne and Goldstein (2001)'s parameters of $\phi=0.18$ and $\nu=-0.6$. We use the same estimated LBO intensity parameters as for the Merton model. The leverage jump size $\eta$ is estimated in the same way as for the Merton model by minimizing the RMSEs between actual and model-implied price reactions to an LBO, where the model-implied price reaction is calculated as the percentage difference between the price in the standard model without LBO risk and the model with LBO risk. The mean jump size is estimated to $\eta=0.3021$.

Table 7 presents the estimation results. Panel A show that, as was the case in the Merton model, the stationary leverage model captures the historical hump-shaped relation between price reaction around LBOs and maturity. Panel B shows that the effect of LBO risk is similar to that in the Merton model. 
For example, the effect of LBO risk is $13-14$ bps at the 5-year maturity and 18-21bps at the 10-year maturity in both models. It is only for long maturities (20-40 years) that a 7-8 bps difference in spread predictions starts to emerge.

Figure 8 shows the time series variation in spread contribution of LBO risk at a maturity of 10 years in the stationary leverage model, as well as in the Merton model. The spread contribution in the stationary leverage model is slightly higher than in the Merton model, but the time series variation implied by both models is very similar.

In our estimation using structural models we assume that LBOs increase financial leverage, while firm value is assumed unchanged. In practice, any operational improvements associated with the LBO will increase firm value, as well, and this effect will, in isolation, lead to a decrease in spread around the LBO. In this case, bond price changes around LBO events capture the joint effect of both a leverage increase and operational improvements. Since the structural models are calibrated to price changes around an LBO, the model-implied ex-ante impact reflects the net effect of the two opposing factors ${ }^{19}$

\section{Summary}

Although LBO activity is cyclical, LBO volume has generally increased in the past three decades as private equity activity has grown, rendering LBO risk a growing concern for investors in credit markets. This paper studies the impact of LBO risk on bond credit spreads over time, in the cross section, and across bond maturities.

We show that intra-industry credit spreads increase around LBO announcements, consistent with the notion that investors revise upward the probability of future LBOs, leading to higher spreads. To rule out the most obvious alternative explanation of this result - that the increase in spreads is due to lower valuations of firms in the industry - we show that equity returns are significantly positive around the announcement.

We sharpen our analysis further and examine two channels via which LBOs might affect credit

\footnotetext{
${ }^{19}$ In a previous version of the paper, we extended the Merton model to allow for log-normal distributed jumps in firm value around an LBO. In the extension, log amount of debt jumps by $J_{K}$ where $J_{K} \sim N\left(\eta_{K}, \varsigma_{K}\right)$ and log firm value jumps by $J_{V}$ where $J_{V} \sim N\left(\eta_{V}, \varsigma_{V}\right)$. We showed that bond prices in the extended model can be written as bond prices in the model with only $\log$ debt jumps $J \sim N(\eta, \varsigma)$, where $\eta=\eta_{K}-\eta_{V}$ and $\varsigma=\sqrt{\varsigma_{K}^{2}+\varsigma_{V}^{2}}$. This implies that investigating the joint effect on credit spreads is isomorphic to modeling the joint effect as arising solely through a jump in debt.
} 
spreads. One channel is a widening in spreads due to increased leverage post LBO. We isolate the contribution of this channel by comparing, at the same time and for the same firm, the difference in yield between bonds with an event risk covenant and bonds without. We find an average sizeable difference of 21 basis points. This identification strategy allows us to control for firms' credit quality non-parametrically and, therefore, provides strong support for the leverage effect being economically significant. Another potential channel is a change in spread due to the disciplining effect of LBOs, i.e. managers cannot lead "the quiet life" when a takeover threat is looming. To investigate this channel, we exploit the fact that all corporate bonds are exposed to the disciplining effect, but bonds with event risk covenants are not exposed to the leverage effect. Specifically, we isolate the disciplining effect by examining yield changes of bonds with event risk covenants around intra-industry LBO announcements. In the month around the announcement the average yield change of these bonds is small, lending little support to the economic significance of the disciplining effect.

Based on these empirical results, we incorporate the leverage effect in two structural credit models. We do so by letting the firm be exposed to a time varying probability of an LBO, in which case the firm's outstanding debt jumps. Importantly, we calibrate the models to two measurements in the data that differentiate LBO risk from those risks stemming from other corporate events: the frequency of LBOs and the ex-post impact of LBOs on bond prices. The calibrated structural models allow us to study the contribution to credit spreads over time (1980-2014) and across bond maturities.

We find that the contribution of LBO risk to 10-year credit spreads varies substantially from 11-14 basis points in the early eighties to 24-30 basis points in high LBO periods, such as 2005-2007 (preceding the financial crisis), underpinning the increased significance of LBO risk in credit pricing. We also find that the effect of LBO risk is hump-shaped with respect to maturity, and the effect is strongest for bonds with a remaining maturity of 10-20 years, consistent with historical evidence.

Our results further the understanding of the variation in bond credit spreads. According to standard structural models, only firm-specific variables, such as leverage and asset volatility, affect spreads. Yet Collin-Dufresne et al. (2001) find that a significant fraction of bond spread changes is explained by a common factor unrelated to firm-specific variables and bond market liquidity. LBO risk can help explain these findings, as an increasingly significant, unaccounted-for common risk. Corporate issuers have been increasingly exposed to potentially hostile takeovers, which result in a dramatic change in 
risk profile, particularly for investment-grade firms. While buyout activity is subject to recurring boom and bust cycles, a significant part of the growth in private equity activity is, according to Kaplan and Stromberg (2009), believed to be permanent. 


\section{References}

Asquith, P., Wizmann, A., 1990. Event risk, covenants, and bondholder returns in leveraged buyouts. Journal of Financial Economics 27, 195-212.

Bao, J., Pan, J., Wang, J., 2011. The illiquidity of Corporate Bonds. Journal of Finance 66, 911-946.

Baran, L., King, T.-H. D., 2010. Going private transactions, bondholder returns, and wealth transfer effects. Journal of Banking and Finance 34, 1856-1872.

Bertrand, M., Mullainathan, S., 2003. Enjoying the quiet life? Corporate governance and managerial preferences. Journal of Political Economy 11, 1043-1075.

Bessembinder, H., Kahle, K. M., Maxwell, W. F., Xu, D., 2009. Measuring abnormal bond performance. Review of Financial Studies 22, 4219-4258.

Billett, M., Jiang, Z., Lie, E., 2010. The effect of change-of-control covenants on takeovers: Evidence from leveraged buyouts. Journal of Corporate Finance 16, 1-15.

Billett, M., King, T.-H. D., Mauer, D., 2007. Growth Opportunities and the Choice of Leverage, Debt Maturity, and Covenants. Journal of Finance 62, 697-730.

Boehmer, E., Musumeci, J., Poulsen, A., 1991. Event-study methodology under conditions of eventinduced variance. Journal of Financial Economics 50, 253-272.

Bradley, M., Roberts, M., 2015. The Structure and Pricing of Corporate Debt Covenants. Quarterly Journal of Finance 5, 1550001.

Cain, M. D., McKeon, S. B., Solomon, S. D., 2016. Do Takeover Laws Matter? Evidence from Five Decades of Hostile Takeovers, forthcoming, Journal of Financial Economics.

Campani, C. H., Goltz, F., 2011. A review of corporate bond indices: Construction principles, return heterogeneity, and fluctuations in risk exposures. Unpublished Manuscript, EDHEC-RISK Institute pp. 1-68.

Chen, L., Collin-Dufresne, P., Goldstein, R. S., 2009. On the relation between the credit spread puzzle and the equity premium puzzle. Review of Financial Studies 22, 3367-3409. 
Collin-Dufresne, P., Goldstein, R., 2001. Do Credit Spreads Reflect Stationary Leverage Ratios? Journal of Finance 56, 1929-1957.

Collin-Dufresne, P., Goldstein, R., Martin, S., 2001. The Determinants of Credit Spread Changes. Journal of Finance 56, 2177-2207.

Comment, R., Schwert, G. W., 1995. Poison or placebo? Evidence on the deterrence and wealth effects of modern antitakeover measures. Journal of Financial Economics 39, 3-43.

Cox, J., Ingersoll, J., Ross, S., 1985. A Theory of the Term Structure of Interest Rates. Econometrica $53,385-407$.

Crabbe, L., 1991. Event Risk: An Analysis of Losses to Bondholders and "Super Poison Put" Bond Covenants. Journal of Finance 46, 689-706.

Dick-Nielsen, J., 2009. Liquidity biases in TRACE. Journal of Fixed Income 19, 43-55.

Dick-Nielsen, J., 2014. How to Clean Enhanced TRACE Data. Unpublished Manuscript .

Dick-Nielsen, J., Feldhütter, P., Lando, D., 2012. Corporate bond liquidity before and after the onset of the subprime crisis. Journal of Financial Economics 103, 471-492.

Feldhütter, P., Lando, D., 2008. Decomposing Swap Spreads. Journal of Financial Economics 88, 375405.

Feldhütter, P., Schaefer, S., 2018. The Myth of the Credit Spread Puzzle. Review of Financial Studies $8,2897-2942$.

Flannery, M. J., Nikolova, S., Oztekin, O., 2012. Leverage Expectations and Bond Credit Spreads. Journal of Financial and Quantitative Analysis 47, 689-714.

Francis, B., Hasan, I., John, K., Waisman, M., 2010. The effect of state antitakeover laws on the firm's bondholders. Journal of Financial Economics 96, 127-154.

Friewald, N., Jankowitsch, R., Subrahmanyam, M. G., 2012. Illiquidity or credit deterioration: a study of liquidity in the US corporate bond market during financial crises. Journal of Financial Economics $105,18-36$. 
Harford, J., Stanfield, J., Zhang, F., 2016. How does an LBO impact the target's industry? Working Paper .

Helwege, J., Huang, J.-Z., Wang, Y., 2016. Debt Covenants and Cross-Sectional Equity Returns. Management Science 63, 1835-1854.

Innes, R. D., 1990. Limited Liability and Incentive Contracting with Ex-ante Action Choices. Journal of Economic Theory 52, 45-67.

Jensen, M., 1986. Agency Costs of Free Cash Flow, Corporate Finance, and Takeovers. American Economic Review 76, 323-329.

Jensen, M., Meckling, W., 1976. Theory of the Firm: Managerial Behavior, Agency Costs and Ownership Structure. Journal of Financial Economics 3, 305-360.

Kaplan, S. N., Stromberg, P., 2009. Leveraged Buyouts and Private Equity. Journal of Economic Perspectives $23,121-146$.

Kladıvko, K., 2007. Maximum likelihood estimation of the cox-ingersoll-ross process: the matlab implementation. In: Technical Computing Prague, working paper.

Lando, D., 1998. On cox processes and credit-risky securities. Review of Derivatives Research 2, 99-120.

Loon, Y. C., Zhong, Z. K., 2014. The impact of central clearing on counterparty risk, liquidity, and trading: Evidence from the credit default swap market. Journal of Financial Economics 112, 91-115.

Marais, L., Schipper, K., Smith, A., 1989. Wealth effects of going private for senior securities. Journal of Financial Economics 23, 155-191.

Merton, R., 1974. On the Pricing of Corporate Debt: The Risk Structure of Interest Rates. Journal of Finance 29, 449-470.

Micu, M., Remolona, E., Wooldridge, P., 2006. The Pricing Impact of Rating Announcements: Which announcements matter? BIS Working Paper .

Mitchell, M., Mulherin, H., 1996. The Impact of Industry Shocks on Takeover and Restructuring Activity. Journal of Financial Economics 41, 193-229. 
Moody's, 2013. Annual Default Study: Corporate Default and Recovery Rates, 1920-2012. Moody's Investors Service pp. 1-64.

Qiu, J., Yu, F., 2009. The market for corporate control and the cost of debt. Journal of Financial Economics 93, 505-524.

Roades, S., Rutz, R., 1982. MARKET POWER AND FIRM RISK A Test of the 'Quiet Life' Hypothesis. Journal of Monetary Economics pp. 73-85.

Smith, C., Warner, J., 1979. On Financial Contracting: An Analysis of Bond Covenants. Journal of Financial Economics 7, 117-161.

Warga, A., Welch, I., 1993. Bondholder losses in leveraged buyouts. Review of Financial Studies pp. 959-982. 


\section{Appendix A. Event study methodology}

In this appendix we describe the event study methodology used in the paper.

\section{A.1. $C D S$}

Daily returns To measure the effect of the LBO announcements on CDS spreads, we follow Micu, Remolona, and Wooldridge (2006), Loon and Zhong (2014) and others and study normalized changes in spreads. In particular, for issuer $i$ at time $t$ the normalized change in spread is

$$
R_{i, t}=\log \left(\frac{s_{i, t}}{s_{i, t-1}}\right)
$$

where $s_{i, t}$ is the CDS premium for issuer $i$ on day $t$.

Abnormal returns Abnormal return is computed over a market-wide CDS index. The index is calculated daily as the average 5-year CDS premium across all firms in the sample. We use the marketadjusted model with an estimation window of 100 days, i.e. approximately 70 business days, and include only events where there are spread changes on at least half of the days in the estimation window.

Abnormal returns in the market-adjusted model are computed as:

$$
A R_{i, t}=R_{i, t}-\left(\alpha_{i}+\beta_{i} R_{M, t}\right)
$$

where $A R_{i, t}$ is the abnormal return for issuer $i$ on day $t, R_{i, t}$ is the return for issuer $i$ on day $t$ (calculated according to equation (17)), $R_{M, t}$ is the return on the index on day $t$ (computed similarly to issuer return), and $\alpha_{i}$ and $\beta_{i}$ are estimated in a regression of issuer $i$ returns against the index over the estimation window.

In computing the significance of the abnormal return, we address two issues which may affect the variance. First is the error in the estimation of $\alpha_{i}$ and $\beta_{i}$ and, second, LBO announcements could potentially lead to a change in the variance of CDS spreads due to a change in the firm's risk. We use Boehmer, Musumeci, and Poulsen (1991)'s test statistics, which correct for both issues (see Micu et al. 2006 for details). 


\section{A.2. Equity}

Stock prices are from CRSP and abnormal returns and t-statistics are computed in the same way as for CDS spreads described above, except that the equity returns are calculated as

$$
R_{i, t}=\log \left(\frac{P_{i, t}}{P_{i, t-1}}\right)
$$

The market-adjusted model is calculated using the S\&P 500 index as the market.

\section{A.3. Corporate bonds}

Daily returns Daily corporate bond returns are defined as

$$
R_{i, t}=\log \left(\frac{P_{i, t}}{P_{i, t-1}}\right)
$$

We calculate daily bond prices as the average price across all transactions on that day. If there are no transactions on a specific day in the event window, we use the last available daily price. If there are more than five days in the event window with missing prices we discard the bond.

Abnormal returns Abnormal return is computed over the Bank of America Merrill Lynch US Corporate Bond Master Index (see Campani and Goltz, 2011 for a review of corporate bond indices). We use a market-adjusted model with an estimation window of 30 days, i.e. approximately 22 business days. We use a shorter estimation window than for CDS and equity returns because a significant number of bonds do not have a long enough transaction history and we set $\alpha_{i}$ in equation (18) to zero for stability.

To calculate a t-statistic we calculate the mean, $\mu$ and standard deviation, $\sigma$, of the cross-section of cumulative abnormal returns for all bonds as suggested by Bessembinder, Kahle, Maxwell, and Xu (2009). To account for the correlation between returns of bonds issued by the same firm we use the number of firms, $N_{f}$, as the degrees of freedom. Thus, the t-statistic is

$$
\frac{\sqrt{N_{f}} \mu}{\sigma}
$$

This test assumes that returns of bonds issued by the same firm are perfectly correlated. This may not be the case and therefore this t-statistic is conservative, i.e. is less likely to reject a null hypothesis. 


\section{Appendix B. Structural models with LBO risk}

In this Appendix we derive credit spreads in two structural models with LBO risk. The first is the Merton model (as implemented in Chen et al., 2009) and the second is Collin-Dufresne and Goldstein (2001)'s stationary leverage model.

Assume that firm value follows a Geometric Brownian Motion under the risk-neutral measure

$$
\frac{d V_{t}}{V_{t}}=(r-\delta) d t+\sigma d W_{t}^{V}
$$

where $r$ is the riskfree rate, $\delta$ the payout rate, and $\sigma$ is the asset volatility. We define $y=\log (V)$,

$$
d y_{t}=\left(r-\delta-\frac{1}{2} \sigma^{2}\right) d t+\sigma d W_{t}^{V}
$$

\section{B.1. Merton model with LBO risk}

Assume that the firm has issued one zero-coupon bond with maturity $T$ and face value of $\mathrm{K}$. The firm can only default at bond maturity and it does so if firm value is below the face value of all debt $K_{T}$. If the firm defaults, bondholders receive a fraction $\alpha$ of the face value of debt. If the firm has not undergone an LBO between time 0 and $T$, there is only one bond outstanding and the face value of debt at time $T$ is equal to the face value of debt at time 0 , namely $\mathrm{K}$.

The firm can potentially undergo an LBO that occurs at time $\tau$, after which no further LBOs can occur. Upon an LBO, the firm issues more debt with the same maturity and seniority as existing debt. The total amount of debt after the LBO is $K e^{J}$, where $J$ is normally distributed with mean $\eta$ and standard deviation $\varsigma$. We assume that the LBO event follows a Cox process with intensity $\lambda_{t}$ (see Lando, 1998). This implies that in a short time interval between $t$ and $t+\Delta$ the probability of an LBO occurring is approximately $\lambda_{t} \Delta$. We assume that $\lambda_{t}$ follows a CIR process,

$$
d \lambda_{t}=\kappa\left(\theta-\lambda_{t}\right) d t+\xi \sqrt{\lambda_{t}} d W_{t}^{\lambda}
$$

We assume that there is no risk premium associated with LBO risk, such that the dynamics of LBO risk are the same under the natural and risk-neutral measure. If we are at time 0 and define the expected 
payoff at maturity $T$ of the risky zero coupon bond as $w(T)$ we have that

$$
\begin{aligned}
w(T) & =E\left[1_{\left\{V_{T}>K_{T}\right\}}+\alpha 1_{\left\{V_{T} \leq K_{T}\right\}}\right] \\
& =E\left[\alpha+(1-\alpha) 1_{\left\{V_{T}>K_{T}\right\}}\right] \\
& =E\left[\alpha+(1-\alpha) 1_{\left\{V_{T}>K_{T}\right\}} \mid \tau>T\right] P(\tau>T)+E\left[\alpha+(1-\alpha) 1_{\left\{V_{T}>K_{T}\right\}} \mid \tau \leq T\right] P(\tau \leq T) \\
& =E\left[\alpha+(1-\alpha) 1_{\left\{V_{T}>K\right\}}\right] P(\tau>T)+E\left[\alpha+(1-\alpha) 1_{\left\{V_{T}>K e^{J}\right\}}\right] P(\tau \leq T)
\end{aligned}
$$

According to Lando (1998) we have that

$$
P(\tau>T)=E\left[e^{-\int_{0}^{T} \lambda_{s} d s}\right]
$$

and we know from Cox, Ingersoll, and Ross (1985) that

$$
E\left[e^{-\int_{0}^{T} \lambda_{s} d s}\right]=A(T) e^{-B(T) \lambda_{0}}
$$

where

$$
\begin{aligned}
A(T) & =\left(\frac{2 h e^{(h+\kappa) T / 2}}{2 h+(h+\kappa)\left(e^{h T}-1\right)}\right)^{\frac{2 \kappa \theta}{\xi^{2}}} \\
B(T) & =\frac{2\left(e^{h T}-1\right)}{2 h+(h+\kappa)\left(e^{h T}-1\right)} \\
h & =\sqrt{\kappa^{2}+2 \xi^{2}} .
\end{aligned}
$$

Define $L_{t}=\frac{K}{V_{t}}$. We have that

$$
E\left[1_{\left\{V_{T}>K e^{J}\right\}}\right]=P\left(L_{T}<e^{-J}\right)=P\left(\log \left(L_{t}\right)+J<0\right)
$$

and because - using $(23)-\log \left(V_{T}\right)$ is normally distributed with mean $\log \left(V_{0}\right)+\left(r-\delta-\frac{1}{2} \sigma^{2}\right) T$ and variance $\sigma^{2} T$, we have that $\log \left(L_{T}\right)+J$ is normally distributed with mean $\log \left(L_{0}\right)-\left(r-\delta-\frac{1}{2} \sigma^{2}\right) T+\eta$ and variance $\sigma^{2} T+\varsigma^{2}$. Therefore

$E\left[1_{\left\{V_{T}>K e^{J}\right\}}\right]=N\left(\frac{-\log \left(L_{0}\right)+\left(r-\delta-\frac{1}{2} \sigma^{2}\right) T-\eta}{\sqrt{\sigma^{2} T+\varsigma^{2}}}\right)=N\left(\frac{-\log \left(L_{0}\right)+\left(\left[r-\delta-\frac{\eta}{T}+\frac{1}{2} \frac{\varsigma^{2}}{T}\right]-\frac{1}{2}\left[\sigma^{2}+\frac{\varsigma^{2}}{T}\right]\right) T}{\sqrt{\left[\sigma^{2}+\frac{\varsigma^{2}}{T}\right] T}}\right)$

where $N$ is the normal cumulative distribution function. Overall, this implies that the price of the zero coupon bond, $w(T)$ is

$$
w(T)=v^{M}(T) P(\tau>T)+e^{-r T}\left[\alpha+(1-\alpha) E\left[1_{\left\{V_{T}>K e^{J}\right\}}\right][[1-P(\tau>T)]\right.
$$


where

$$
v^{M}(T)=e^{-r T}\left[\alpha+(1-\alpha) N\left(\frac{-\log \left(L_{0}\right)+\left(r-\delta-\frac{1}{2} \sigma^{2}\right) T}{\sqrt{\sigma^{2} T}}\right)\right]
$$

is the price of a zero coupon bond in the standard Merton model without LBO risk.

\section{B.2. A model with stationary leverage ratios and LBO risk}

Assume as in Collin-Dufresne and Goldstein (2001) that the firm targets a long-run leverage ratio and that the dynamics of the log of the amount of debt, $k_{t}$, are given by

$$
d k_{t}=\phi\left(\nu-\left(k_{t}-y_{t}\right)\right) d t
$$

If we define log-leverage as $l_{t}=k_{t}-y_{t}$, then the intuition is that if $l_{t}$ is less than $\nu$, the firm increases the amount of debt and vice versa, i.e. log-leverage is stationary around a mean leverage of $\nu$. This specification captures the idea that the firm tends to issue more debt when leverage is low and tends to retire debt when leverage is high. Ito's Lemma gives that

$$
d l_{t}=\phi\left(\bar{l}-l_{t}\right) d t-\sigma d W_{t}^{V}
$$

where $\bar{l}=\frac{-r+\delta+\frac{1}{2} \sigma^{2}}{\phi}+\nu$. We assume that all debt has equal priority and matures at time $T$, i.e. if the firm issues more debt, it issues more debt with the same maturity and seniority as existing debt. The firm can only default at bond maturity $T$ and it does so if firm value is below the face value of all debt $K_{T}$. If the firm defaults, bondholders receive a fraction $\alpha$ of the face value of debt.

As in the previous section, we assume that the firm can potentially undergo an LBO that occurs at time $\tau$ (and thereafter no more LBOs can occur), in which case the firm issues more debt (with same maturity and seniority as existing debt). To capture that leverage jumps after the LBO and that the target leverage is higher after an LBO, we assume that the total amount of debt immediately after the LBO is $K_{\tau} e^{J}$, where $J$ is normally distributed with mean $\eta$ and standard deviation $\varsigma$, while the target log-leverage after the LBO changes from $\nu$ to $\nu+J$. We assume that the LBO event follows a Cox process with intensity $\lambda_{t}$, where $\lambda_{t}$ follows a CIR process,

$$
d \lambda_{t}=\kappa\left(\theta-\lambda_{t}\right) d t+\xi \sqrt{\lambda_{t}} d W_{t}^{\lambda} .
$$


and that there is no risk premium associated with LBO risk. If we are at time 0 and define the expected payoff at maturity $T$ of the risky zero coupon bond as $w(T)$, we have that

$$
w(T)=E\left[\alpha+(1-\alpha) 1_{\left\{l_{T}>0\right\}} \mid \tau>T\right] P(\tau>T)+E\left[\alpha+(1-\alpha) 1_{\left\{l_{T}>0\right\}} \mid \tau \leq T\right] P(\tau \leq T)
$$

where $P(\tau>T)$ is given in equations 29$)-(33)$.

In the event of no LBO $(\tau>T)$, we have that the dynamics of $l_{t}$ given in equation (39) are an Ornstein-Uhlenbeck process, and it is well-known that the conditional distribution $l_{t} \mid l_{0}, \tau>T$ is normally distributed with mean $\bar{l}+\left(l_{0}-\bar{l}\right) e^{-\phi t}$ and variance $\frac{\sigma^{2}}{2 \phi}\left(1-e^{-2 \phi t}\right)$. This implies that

$$
E\left[1_{\left\{l_{T}>0\right\}} \mid \tau>T\right]=N\left(\frac{\bar{l}+\left(l_{0}-\bar{l}\right) e^{-\phi T}}{\sqrt{\frac{\sigma^{2}}{2 \phi}\left(1-e^{-2 \phi T}\right)}}\right) .
$$

It is useful to define the $l_{t}^{L B O}$ as the leverage process in case of an LBO at time $\tau$ and $l_{t}$ as the leverage process if no LBO happens before $T$. Then $l_{t}^{L B O}=l_{t}$ when $t<\tau$ and $l_{\tau}^{L B O}=l_{\tau}+J$. Because the new target log-leverage is $\nu+J$, the dynamics of log-debt immediately after the LBO are

$$
d k_{\tau}^{L B O}=\phi\left(\nu+J-l_{\tau}^{L B O}\right) d t=\phi\left(\nu+J-\left(l_{\tau}+J\right)\right) d t=\phi\left(\nu-l_{\tau}\right) d t
$$

and we see that $k^{L B O}$ and $k$ have the same rate of change at all times except when leverage jumps at $\tau$. Since asset value is not affected by an LBO, $l^{L B O}$ and $l$ have the same rate of change at all times except at $\tau$, so $l_{t}^{L B O}=l_{t}+J$ for any $t>\tau$. Thus, the conditional distribution $l_{t} \mid l_{0}, \tau \leq T$ is normally distributed with mean $\bar{l}+\left(l_{0}-\bar{l}\right) e^{-\phi t}+\eta$ and variance $\frac{\sigma^{2}}{2 \phi}\left(1-e^{-2 \phi t}\right)+\varsigma^{2}$. Overall, this implies that

$$
E\left[1_{\left\{l_{T}>0\right\}} \mid \tau \leq T\right]=N\left(\frac{\bar{l}+\left(l_{0}-\bar{l}\right) e^{-\phi T}+\eta}{\sqrt{\frac{\sigma^{2}}{2 \phi}\left(1-e^{-2 \phi T}\right)+\varsigma^{2}}}\right) .
$$


Table 1: Event study of CDS, bond, and equity returns of target firms around LBO announcements

\begin{tabular}{|c|c|c|c|c|}
\hline $\begin{array}{c}\text { window } \\
(1)\end{array}$ & $\begin{array}{c}\Delta \mathrm{CDS} \\
(2)\end{array}$ & $\begin{array}{c}\mathrm{E}(\Delta \mathrm{CDS}) \\
(3)\end{array}$ & $\begin{array}{l}\text { abn. return } \\
(4)\end{array}$ & $\begin{array}{c}\text { t-stat } \\
(5)\end{array}$ \\
\hline \multicolumn{5}{|c|}{ Panel A: 5-year CDS } \\
\hline$[-22,-12]$ & 17.4 & 1.6 & 3.90 & 1.68 \\
\hline$[-11,-1]$ & 28.5 & 2.6 & $14.89^{* *}$ & 2.89 \\
\hline$[0,1]$ & 45.4 & 22.7 & $24.65^{*}$ & 2.61 \\
\hline$[2,21]$ & 11.2 & 0.5 & 0.33 & 0.77 \\
\hline$[-22,5]$ & 94.2 & 2.1 & $43.77^{* *}$ & 3.69 \\
\hline \multicolumn{5}{|c|}{ Panel B: All bonds } \\
\hline$[-22,-12]$ & & & -0.99 & -1.19 \\
\hline$[-11,-1]$ & & & -0.73 & -1.32 \\
\hline$[0,1]$ & & & $-2.75^{* *}$ & -3.40 \\
\hline$[2,21]$ & & & 0.22 & 0.34 \\
\hline$[-22,5]$ & & & $-4.18^{* *}$ & -3.71 \\
\hline \multicolumn{5}{|c|}{ Panel C: Unprotected bonds } \\
\hline$[-22,-12]$ & & & -1.18 & -1.02 \\
\hline$[-11,-1]$ & & & -0.84 & -1.11 \\
\hline$[0,1]$ & & & $-3.29^{* *}$ & -3.00 \\
\hline$[2,21]$ & & & 0.20 & 0.18 \\
\hline$[-22,5]$ & & & $-5.05^{* *}$ & -3.35 \\
\hline \multicolumn{5}{|c|}{ Panel D: Protected bonds } \\
\hline$[-22,-12]$ & & & -0.18 & -0.48 \\
\hline$[-11,-1]$ & & & -0.25 & -0.59 \\
\hline$[0,1]$ & & & -0.44 & -0.94 \\
\hline$[2,21]$ & & & 0.38 & 1.01 \\
\hline$[-22,5]$ & & & -0.40 & -0.60 \\
\hline \multicolumn{5}{|c|}{ Panel E: Equity } \\
\hline$[-22,-12]$ & & & $0.49^{*}$ & 2.40 \\
\hline$[-11,-1]$ & & & $1.82^{* *}$ & 3.26 \\
\hline$[0,1]$ & & & $10.86^{* *}$ & 7.47 \\
\hline$[2,21]$ & & & 0.75 & 1.72 \\
\hline$[-22,5]$ & & & $13.58^{* *}$ & 7.80 \\
\hline
\end{tabular}

The first column reports the time window in days relative to the announcement day. The second column reports the average total change in the CDS spread (in basis points) in the window, while the third column reports the average change per day in the CDS spread (in basis points) in the window. The fourth column reports the average total abnormal return (in percent) in the window. The fifth column reports the t-statistics of the average total abnormal return (one star denotes significance at the five-percent level and two stars at the one-percent level). Panel A is based on 42 firm observations, Panel B on 230 bonds (issued by 45 firms), Panel C on 187 bonds (issued by 28 firms), Panel D on 43 bonds (issued by 21 firms), and Panel E on 93 firm observations. The t-statistics in Panels B-D account for return correlation of bonds issued by the same firm. The sample period is 2002-2015. 
Table 2: LBOs in an industry predict additional LBOs

\begin{tabular}{|c|c|c|c|c|}
\hline \multirow[t]{2}{*}{ dep.var: } & \multicolumn{4}{|c|}{$\mathrm{LBO}_{t}^{i}$} \\
\hline & (1) & $(2)$ & $(3)$ & $(4)$ \\
\hline \multicolumn{5}{|c|}{ Panel A: lag of one month } \\
\hline $\mathrm{LBO}_{t-1}^{i}$ & $\begin{array}{c}0.58^{* *} \\
(0.004)\end{array}$ & $\begin{array}{l}0.56^{* *} \\
(0.005)\end{array}$ & $\begin{array}{l}0.37^{* *} \\
(0.005)\end{array}$ & $\begin{array}{l}0.37^{* *} \\
(0.005)\end{array}$ \\
\hline Constant & $\begin{array}{c}0.13^{* *} \\
(0.004)\end{array}$ & & & \\
\hline Number of observations & 34480 & 34480 & 34480 & 34480 \\
\hline adjusted $R^{2}$ & 0.337 & 0.351 & 0.429 & 0.429 \\
\hline time fixed effects & No & Yes & No & Yes \\
\hline industry fixed effects & No & No & Yes & Yes \\
\hline \multicolumn{5}{|c|}{ Panel B: lag of one quarter } \\
\hline $\mathrm{LBO}_{t-1}^{i}$ & $\begin{array}{c}0.81^{* *} \\
(0.006)\end{array}$ & $\begin{array}{l}0.79^{* *} \\
(0.006)\end{array}$ & $\begin{array}{l}0.63^{* *} \\
(0.007)\end{array}$ & $\begin{array}{c}0.63^{* *} \\
(0.007)\end{array}$ \\
\hline Constant & $\begin{array}{c}0.19^{* *} \\
(0.014)\end{array}$ & & & \\
\hline Number of observations & 11440 & 11440 & 11440 & 11440 \\
\hline adjusted $R^{2}$ & 0.636 & 0.643 & 0.675 & 0.675 \\
\hline time fixed effects & No & Yes & No & Yes \\
\hline industry fixed effects & No & No & Yes & Yes \\
\hline \multicolumn{5}{|c|}{ Panel C: lag of one year } \\
\hline $\mathrm{LBO}_{t-1}^{i}$ & $\begin{array}{c}0.97^{* *} \\
(0.008)\end{array}$ & $\begin{array}{l}0.97^{* *} \\
(0.008)\end{array}$ & $\begin{array}{l}0.86^{* *} \\
0.012)\end{array}$ & $\begin{array}{c}0.86^{* *} \\
(0.012)\end{array}$ \\
\hline Constant & $\begin{array}{c}0.35^{* *} \\
(0.072)\end{array}$ & & & \\
\hline Number of observations & 2800 & 2800 & 2800 & 2800 \\
\hline adjusted $R^{2}$ & 0.830 & 0.848 & 0.854 & 0.854 \\
\hline time fixed effects & No & Yes & No & Yes \\
\hline industry fixed effects & No & No & Yes & Yes \\
\hline
\end{tabular}

This tables presents the regression of the number of LBOs at time $t$ in industry $i$ on the number of LBOs at time $t-1$ in the same industry. LBOs are determined according to Thomson Financial LBO announcements in the years 1980-2014. Industry is determined at the 2-digit SIC level. Standard errors are in parentheses. ${ }^{* *}$ and ${ }^{*}$ indicate significance at the 1 and $5 \%$ level, respectively. 
Table 3: Intra-industry reaction of CDS, bond, and equity prices around LBO announcements

\begin{tabular}{|c|c|c|c|c|}
\hline $\begin{array}{c}\text { window } \\
\text { (1) }\end{array}$ & $\begin{array}{c}\Delta \mathrm{CDS} \\
(2)\end{array}$ & $\begin{array}{c}\mathrm{E}(\Delta \mathrm{CDS}) \\
(3)\end{array}$ & $\begin{array}{c}\text { abn. return } \\
\text { (4) }\end{array}$ & $\begin{array}{c}\text { t-stat } \\
(5)\end{array}$ \\
\hline \multicolumn{5}{|c|}{ Panel A: 5-year CDS } \\
\hline$[-22,-12]$ & 0.6 & 0.1 & 0.65 & -0.28 \\
\hline$[-11,-1]$ & 1.0 & 0.1 & 0.93 & 1.17 \\
\hline$[0,1]$ & 1.8 & 0.9 & $3.00^{* *}$ & 3.98 \\
\hline$[2,21]$ & 1.1 & 0.1 & $5.35^{* *}$ & 4.90 \\
\hline$[-22,5]$ & 4.5 & 0.1 & $9.93^{* *}$ & 5.52 \\
\hline \multicolumn{5}{|c|}{ Panel B: All bonds } \\
\hline$[-22,-12]$ & & & -0.04 & -0.32 \\
\hline$[-11,-1]$ & & & $-0.66^{* *}$ & -6.38 \\
\hline$[0,1]$ & & & -0.12 & -1.51 \\
\hline$[2,21]$ & & & -0.10 & -0.47 \\
\hline$[-22,5]$ & & & $-0.95^{* *}$ & -6.27 \\
\hline \multicolumn{5}{|c|}{ Panel C: Unprotected bonds } \\
\hline$[-22,-12]$ & & & -0.08 & -0.76 \\
\hline$[-11,-1]$ & & & $-0.68^{* *}$ & -6.36 \\
\hline$[0,1]$ & & & -0.14 & -1.62 \\
\hline$[2,21]$ & & & -0.08 & -0.38 \\
\hline$[-22,5]$ & & & $-1.02^{* *}$ & -7.44 \\
\hline \multicolumn{5}{|c|}{ Panel D: Protected bonds } \\
\hline$[-22,-12]$ & & & 0.62 & 0.65 \\
\hline$[-11,-1]$ & & & -0.39 & -1.11 \\
\hline$[0,1]$ & & & 0.12 & 0.70 \\
\hline$[2,21]$ & & & -0.33 & -0.68 \\
\hline$[-22,5]$ & & & 0.10 & 0.20 \\
\hline \multicolumn{5}{|c|}{ Panel E: Equity } \\
\hline$[-22,-12]$ & & & 0.22 & 0.86 \\
\hline$[-11,-1]$ & & & -0.34 & -1.75 \\
\hline$[0,1]$ & & & $0.91^{* *}$ & 9.99 \\
\hline$[2,21]$ & & & -0.39 & -1.77 \\
\hline$[-22,5]$ & & & $0.74^{* *}$ & 3.31 \\
\hline
\end{tabular}

For every LBO announcement, this event study examines the CDS, equity, and bond returns of all firms in the same industry as the LBO target (excluding the LBO target itself). Industry is defined according to 2-digit SIC code. The first column reports the time window in days relative to the announcement day. The second column reports the average total change in the CDS spread (in basis points) in the window, while the third column reports the average change per day in the CDS spread (in basis points) in the window. The fourth column reports the average total abnormal return (in percent) in the window. The fifth column reports the t-statistics of the average total abnormal return (one star denotes significance at the five-percent level and two stars at the one-percent level). Panel A is based on 462 firm observations, Panel B on 1148 bonds (issued by 333 firm), Panel C on 1075 bonds (issued by 312 firms), Panel D on 73 bonds (issued by 30 firms), and Panel E on 524 firm observations. The t-statistics in Panels B-D account for return correlation of bonds issued by the same firm. The sample period is 2002-2015. 
Table 4: Event risk covenant regression as in Crabbe (1991)

\begin{tabular}{|c|c|c|c|c|c|c|c|c|}
\hline & $\begin{array}{c}(1) \\
\text { mean }\end{array}$ & $(2)$ & (3) & (4) & $\begin{array}{c}\text { (5) } \\
\text { quantiles }\end{array}$ & (6) & (7) & (8) \\
\hline & & 0.05 & 0.10 & 0.25 & 0.50 & 0.75 & 0.90 & 0.95 \\
\hline Intercept & $\begin{array}{l}46.10 \\
(38.90)\end{array}$ & -145.51 & -116.10 & -63.00 & 16.07 & 112.17 & 186.40 & 314.56 \\
\hline Event risk covenant & $\begin{array}{l}8.59^{*} \\
(3.38)\end{array}$ & -18.35 & -9.48 & -2.94 & 6.51 & 18.69 & 29.92 & 33.56 \\
\hline $\mathrm{AA}+$ & $\begin{array}{l}0.49 \\
(2.94)\end{array}$ & -40.22 & -21.45 & 0.00 & 0.00 & 5.90 & 19.39 & 32.97 \\
\hline AA & $\begin{array}{l}5.50 \\
(4.51)\end{array}$ & -56.69 & -39.71 & -6.88 & 8.13 & 21.09 & 40.49 & 49.94 \\
\hline AA- & $\begin{array}{c}11.57^{* *} \\
(4.18)\end{array}$ & -55.07 & -33.53 & -6.25 & 13.67 & 33.18 & 45.54 & 57.65 \\
\hline$A+$ & $\begin{array}{c}26.19^{* *} \\
(5.12)\end{array}$ & -43.85 & -23.11 & 6.72 & 29.72 & 43.79 & 63.44 & 80.00 \\
\hline $\mathrm{A}$ & $\begin{array}{c}33.28^{* *} \\
(5.21)\end{array}$ & -29.28 & -11.21 & 16.13 & 35.16 & 51.27 & 72.69 & 89.46 \\
\hline A- & $\begin{array}{c}62.10^{* *} \\
(10.03)\end{array}$ & -29.07 & 7.81 & 37.15 & 55.74 & 83.51 & 111.33 & 159.86 \\
\hline $\mathrm{BBB}+$ & $\begin{array}{c}92.24^{* *} \\
(15.10)\end{array}$ & 18.47 & 35.41 & 60.95 & 80.43 & 103.95 & 148.46 & 235.81 \\
\hline BBB & $\begin{array}{c}114.48^{* * *} \\
(16.87)\end{array}$ & 28.39 & 45.55 & 71.54 & 107.34 & 141.91 & 178.45 & 237.34 \\
\hline BBB- & $\begin{array}{c}162.68^{* *} \\
(20.47)\end{array}$ & 51.61 & 77.79 & 109.90 & 151.34 & 202.93 & 262.07 & 319.01 \\
\hline Maturity & $\begin{array}{c}-4.28^{*} \\
(2.07)\end{array}$ & -22.53 & -16.34 & -7.08 & -0.98 & 1.68 & 3.45 & 5.08 \\
\hline Maturity $^{2}$ & $\begin{array}{l}0.13^{*} \\
(0.05)\end{array}$ & -0.12 & -0.05 & -0.01 & 0.05 & 0.21 & 0.43 & 0.60 \\
\hline Call & $\begin{array}{l}-9.65 \\
(5.40)\end{array}$ & -50.59 & -37.98 & -22.20 & -9.51 & 4.54 & 17.03 & 25.10 \\
\hline Log amount outstanding & $\begin{array}{l}4.99^{*} \\
(2.01)\end{array}$ & -8.50 & -6.14 & -0.59 & 5.37 & 10.56 & 15.80 & 20.44 \\
\hline Number of observations & 259 & 147 & 152 & 201 & 253 & 326 & 374 & 400 \\
\hline$R^{2}$ & 0.52 & 0.33 & 0.38 & 0.46 & 0.53 & 0.59 & 0.62 & 0.65 \\
\hline $\mathrm{E}($ Yield spread $)$ & 161.21 & 97.41 & 107.12 & 124.16 & 140.16 & 174.19 & 214.88 & 306.12 \\
\hline
\end{tabular}

We estimate monthly cross-sectional regressions as in Crabbe(1991) over the period 2002:07-2015:09. The table presents the distribution of the coefficients from the resulting 159 regressions. The sample in a given month includes senior unsecured U.S. industrial bonds issued in the previous 14 months, with a maturity of at least 7 years and a rating of BBB- or higher, and excludes puttable, convertible, asset-backed, and variable-coupon bonds. The dependent variable is the bond yield spread (relative to a maturity-matched Treasury yield) and is based on the last transaction in the TRACE database for the bond in the corresponding month. Each month negative yield spreads are set to 0 and winsorized at the $99 \%$. 'Event risk covenant' is 1 if the bond has an event risk covenant and 0 otherwise. The variables AA+ to BBB- are dummy variables for the bond rating at transaction date and 'Maturity' is the remaining time to maturity (in years) at transaction date. 'Call' is 1 if the bond is callable and 0 otherwise. 'Log amount outstanding' is the log of the face value (in USD) of the issue. For a given month 'Sample size' is the number of yield spread observations, 'E(Yield spread)' is the average yield spread, and ' $R^{2}$ ' is the $R^{2}$ of the cross sectional regression. The parentheses in the panel show adjusted Fama-MacBeth standard errors and '*' denotes significance at the $5 \%$ level and '**', at the $1 \%$ level. 
Table 5: Sample of bonds of firms that have bonds both with and without an event risk covenant

\begin{tabular}{lcc}
\hline & protected bonds & unprotected bonds \\
\hline Maturity (in years) & 17.09 & 18.39 \\
Log amount (in USD) outstanding & 13.15 & 12.08 \\
Other covenants & 0.176 & 0.110 \\
Amihud $\left(\times 10^{9}\right)$ & 2,180 & 8,229 \\
Roll & 0.0113 & 0.0141 \\
Number of observations & 14,850 & 14,066 \\
\hline
\end{tabular}

This table provides summary statistics of the bonds used in a panel regression that examines the relation between yield spreads and inclusion of an event risk covenant. We restrict the sample to senior unsecured USD-denominated industrial bonds with a maturity of more than seven years and an investment grade rating (BBB- or higher), and exclude non-callable, puttable, convertible, asset-backed, and variable-coupon bonds. In a given month we, then, use only bonds issued by firms that have at least one bond outstanding with an event risk covenant and at least one bond outstanding without. We do this for 159 months in the sample period 2002:07-2015:09. The yield spread (relative to a maturity-matched Treasury yield) in a given month is based on the last transaction in the TRACE database for the bond in the corresponding month (each month negative yield spreads are set to 0 and winsorized at 99\%). 'Maturity' is the remaining time to maturity (in years) at transaction date. A bond can have up to 47 covenants, excluding the event risk covenant, and 'other covenants' is $\frac{\text { number of other covenants }}{47}$. 'Log amount outstanding' is the log of the face value (in USD) of the issue. 'Amihud' and 'Roll' are bond liquidity measures calculated using all transactions within the month following the methodology in Dick-Nielsen, Feldhütter, and Lando (2012). 'Number of observations' is the number of yield spread observations. 
Table 6: Event risk covenant regression based on bonds of firms that have bonds both with and without an event risk covenant

\begin{tabular}{|c|c|c|c|c|c|c|c|}
\hline dep. var. & $(1)$ & $(2)$ & $(3)$ & $\begin{array}{l}\text { Yield spread } \\
\text { (4) }\end{array}$ & $(5)$ & $(6)$ & $(7)$ \\
\hline Event risk covenant & $\begin{array}{l}-25.04^{* *} \\
(3.94)\end{array}$ & $\begin{array}{l}-26.20^{* *} \\
(3.20)\end{array}$ & $-21.02^{* *}$ & $\begin{array}{l}-20.66^{* *} \\
(2.71)\end{array}$ & $\begin{array}{l}-20.65^{* *} \\
(2.71)\end{array}$ & $\begin{array}{l}-20.67^{* *} \\
(2.71)\end{array}$ & $\begin{array}{c}-20.67^{* *} \\
(2.71)\end{array}$ \\
\hline Other covenants & & $\begin{array}{l}10.99 \\
(36.61)\end{array}$ & $\begin{array}{c}-13.11 \\
(31.95)\end{array}$ & $\begin{array}{c}-10.37 \\
(31.79)\end{array}$ & $\begin{array}{l}-10.37 \\
(31.79)\end{array}$ & $\begin{array}{l}-10.34 \\
(31.81)\end{array}$ & $\begin{array}{c}-10.33 \\
(31.80)\end{array}$ \\
\hline Log amount outstanding & & $\begin{array}{l}1.22 \\
(5.23)\end{array}$ & $\begin{array}{l}1.64 \\
(3.94)\end{array}$ & $\begin{array}{l}1.09 \\
(3.94)\end{array}$ & $\begin{array}{l}1.09 \\
(3.94)\end{array}$ & $\begin{array}{l}1.09 \\
(3.94)\end{array}$ & $\begin{array}{l}1.09 \\
(3.94)\end{array}$ \\
\hline Maturity & & & $\begin{array}{c}1.16^{* *} \\
(0.15)\end{array}$ & $\begin{array}{l}1.82^{* *} \\
(0.18)\end{array}$ & $\begin{array}{l}1.82^{* *} \\
(0.18)\end{array}$ & $\begin{array}{l}1.82^{* *} \\
(0.18)\end{array}$ & $\begin{array}{c}1.82^{* *} \\
(0.18)\end{array}$ \\
\hline Maturity $^{2}$ & & & & $\begin{array}{c}-0.01^{* *} \\
(0.002)\end{array}$ & $\begin{array}{c}-0.01^{* *} \\
(0.002)\end{array}$ & $\begin{array}{c}-0.01^{* *} \\
(0.002)\end{array}$ & $\begin{array}{c}-0.01^{* *} \\
(0.002)\end{array}$ \\
\hline Amihud $\left(\times 10^{9}\right)$ & & & & & $\begin{array}{l}0.40 \\
(0.38)\end{array}$ & & $\begin{array}{l}0.67 \\
(0.50)\end{array}$ \\
\hline Roll & & & & & & $\begin{array}{l}-3.48 \\
(6.01)\end{array}$ & $\begin{array}{l}-5.40 \\
(5.69)\end{array}$ \\
\hline Mean dependent variable & 181.13 & 181.13 & 181.13 & 181.13 & 181.13 & 181.13 & 181.13 \\
\hline Number of observations & 28,916 & 28,916 & 28,916 & 28,916 & 28,916 & 28,916 & 28,916 \\
\hline Number of firms & 136 & 136 & 136 & 136 & 136 & 136 & 136 \\
\hline$R^{2}$ & 0.837 & 0.837 & 0.849 & 0.850 & 0.850 & 0.850 & 0.850 \\
\hline firm $\times$ month fixed effects & Yes & Yes & Yes & Yes & Yes & Yes & Yes \\
\hline
\end{tabular}

This table presents the results of a panel regression of bond yield spreads on an event risk covenant dummy and controls. We restrict the sample to senior unsecured USD-denominated industrial bonds with a maturity of at least seven years and an investment grade rating (BBB- or higher), and exclude non-callable, puttable, convertible, asset-backed, and variablecoupon bonds. In a given month we, then, use only firms that have at least one bond outstanding with an event risk covenant and at least one bond outstanding without. We do this for 159 months in the sample period 2002:07-2015:09 and estimate a panel regression. The dependent variable is the bond yield spread (relative to a maturity-matched Treasury yield) and is based on the last transaction in the TRACE database for the bond in the corresponding month. Each month negative yield spreads are set to 0 and winsorized at $99 \%$. 'Event risk covenant' is 1 if the bond has an event risk covenant and 0 otherwise. A bond can have up to 47 covenants, excluding the event risk covenant, and 'other covenants' is $\frac{\text { number of other covenants }}{47}$. 'Log amount outstanding' is the log of the face value (in USD) of the issue. 'Maturity' is the remaining time to maturity (in years) at transaction date. 'Amihud' and 'Roll' are bond liquidity measures calculated using all transactions within the month following the methodology in Dick-Nielsen, Feldhütter, and Lando (2012). 'Number of observations' is the number of yield spread observations and 'Mean dependent variable' is the average yield spread. The parentheses in the panels show standard errors, clustered at the firm level. ' ${ }^{*}$ ' denotes significance at the $5 \%$ level and '**, at the $1 \%$ level. 
Table 7: Contribution of LBO risk to credit spreads across maturities

\begin{tabular}{|c|c|c|c|c|c|c|c|c|c|c|c|c|}
\hline \multicolumn{13}{|c|}{ Panel A: Ex-post reaction to LBO (in percent) } \\
\hline Bond maturity (in years) & $0-2$ & $2-4$ & $4-6$ & $6-8$ & $8-10$ & $10-20$ & $20-40$ & & & & & \\
\hline Data & -0.5 & -0.8 & -3.6 & -6.8 & -8.7 & -9.0 & -7.7 & & & & & \\
\hline Merton model & -0.1 & -3.3 & -5.8 & -7.0 & -7.5 & -7.4 & -5.3 & & & & & \\
\hline Stationary leverage model & -0.0 & -2.3 & -5.0 & -6.8 & -7.9 & -8.9 & -7.1 & & & & & \\
\hline \multicolumn{13}{|c|}{ Panel B: Ex-ante contribution of LBO risk to credit spreads (in basis points) } \\
\hline Bond maturity (in years) & 1 & 2 & 3 & 4 & 5 & 6 & 7 & 10 & 15 & 20 & 25 & 30 \\
\hline Merton model & 1.8 & 5.5 & 9.0 & 11.7 & 13.7 & 15.2 & 16.2 & 17.6 & 17.8 & 17.0 & 15.9 & 14.8 \\
\hline Stationary leverage model & 0.4 & 3.1 & 6.9 & 10.3 & 13.2 & 15.5 & 17.4 & 21.0 & 23.5 & 23.8 & 23.4 & 22.7 \\
\hline
\end{tabular}

For a typical firm with leverage of $33 \%$ and asset volatility of $24 \%$, we calculate the contribution of LBO risk to the credit spread in the structural models as outlined in Section 4.3 Panel A shows the actual and model-implied bond price reactions to an LBO announcement. Actual bond price reactions are calculated using the same set of unprotected bonds as those used in Table 1 and the reaction is for the event period $[-22 ; 5]$. Panel $\mathrm{B}$ shows the difference (in basis points) in model-implied credit spreads with and without LBO risk. The intensity of an LBO in the structural model is given as $d \lambda_{t}=\kappa\left(\theta-\lambda_{t}\right) d t+\xi \sqrt{\lambda_{t}} d W_{t}^{\lambda}$ and if an LBO happens, the log change in the face value of debt is distributed $J \sim N(\eta, \varsigma)$. The LBO intensity parameters are estimated in Section 4.3 to be $\kappa=0.1946, \theta=0.0215, \xi=0.0511$. In the estimation of the contribution of LBO risk to credit spreads in Panel B, we set the value of $\lambda$ equal to the average LBO probability during 1980-2014 of 0.0183. The leverage jump standard deviation is set to $\varsigma=0.2$ and the jump mean $\eta$ is estimated for each of the two structural models such that the RMSE of the mean difference between the percentage bond price reaction across bond maturities in the data and in the model is minimized. The estimated jump mean is $\eta^{\text {Merton }}=0.4216$ in the Merton model and $\eta^{\text {stationary leverage }}=0.3021$ in the stationary leverage model. 


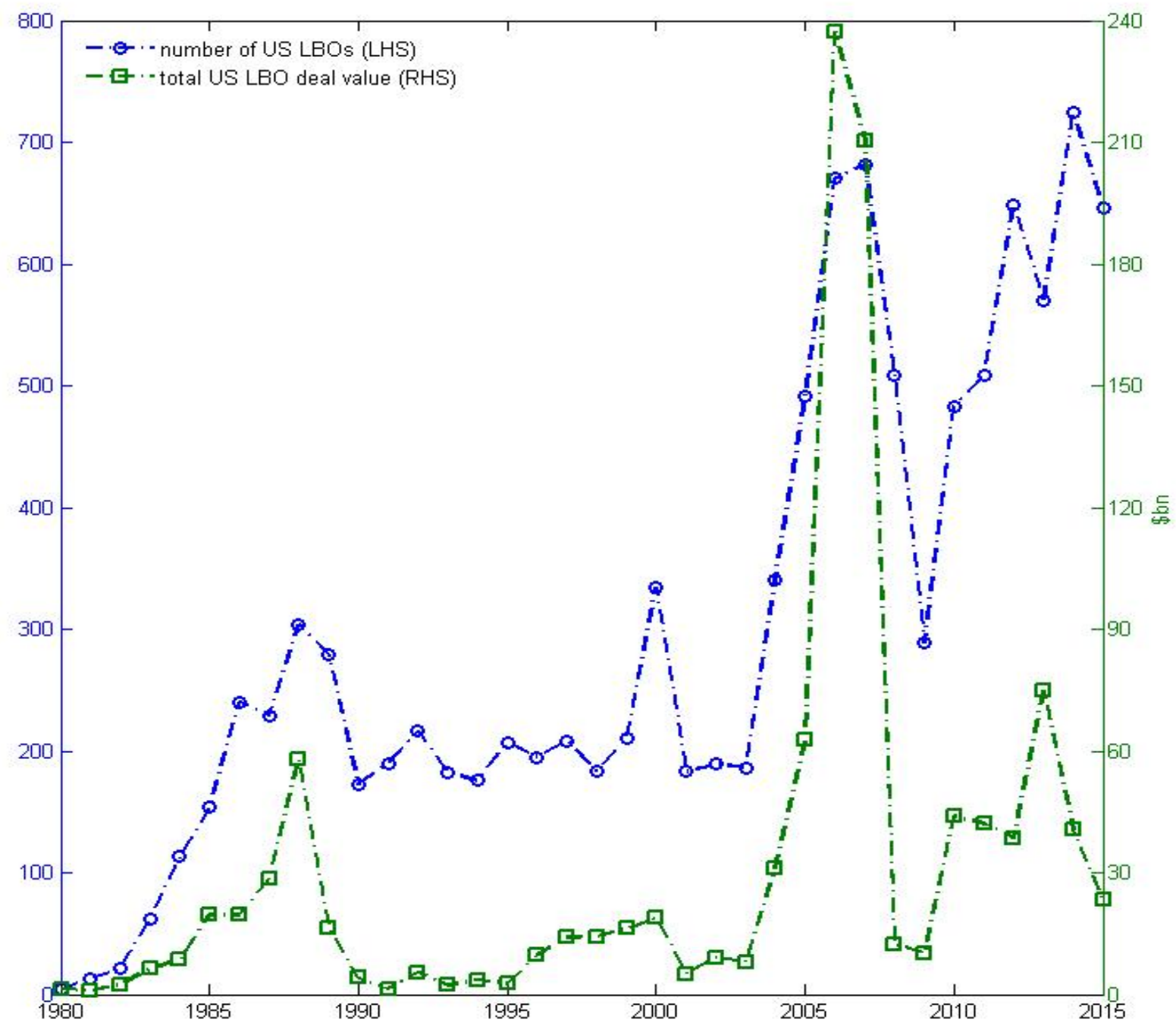

Fig. 1. LBO activity 1980-2015. This figure displays the number (left axis) and total value (right axis, in billions of dollars) of announcements on US LBO targets over the years 1980-2015. Total value is calculated as the total value of equity of target firms and constitutes a lower bound on the actual value, as only $16.2 \%$ of deals have information on the value of equity (likely because the target in those deals is not a public company). Data on LBO announcements are retrieved from Thomson One Banker. 

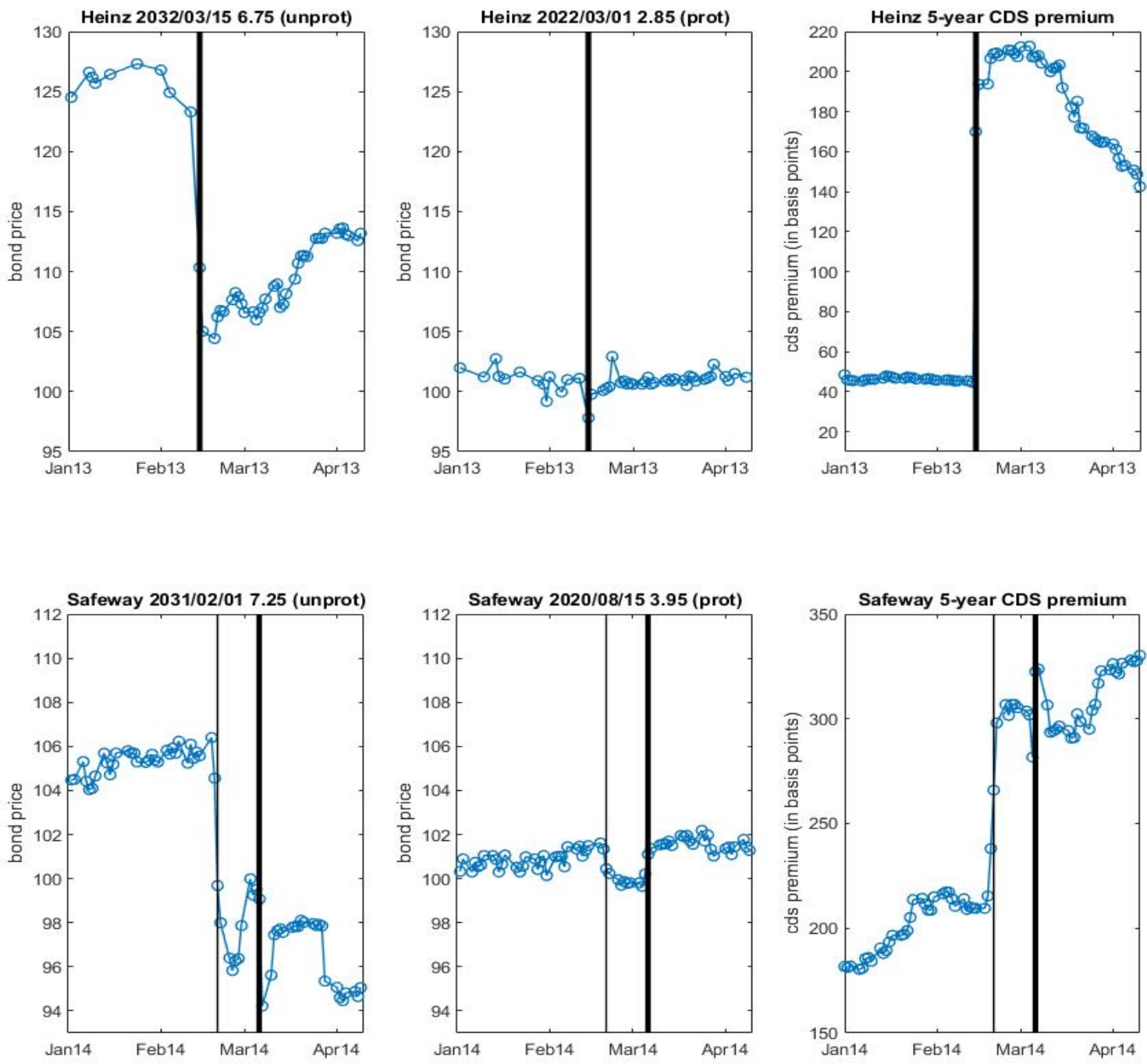

Fig. 2. Heinz and Safeway bond prices and CDS premia around LBO announcements. The top three graphs show Heinz bond prices and 5-year CDS premium and the vertical line marks February 14, 2013, the date where Heinz was taken private in an LBO deal. The Heinz bond expiring 2032 had no event risk covenant, while the 2022 Heinz bond had such a covenant. The bottom three graphs show Safeway bond prices and 5-year CDS premium. On February 19, 2014 Safeway announced that it was "in discussions concerning a possible transaction involving the sale of the company" and this date is marked with a thin vertical line. The thick vertical line marks March 6, 2014, when it was announced that Safeway was bought out in an LBO deal. The 2031 Safeway bond had no event risk covenant, while the 2020 Safeway bond did have an event risk covenant. The bond price on a given day is calculated as the average price of all transactions in TRACE. 

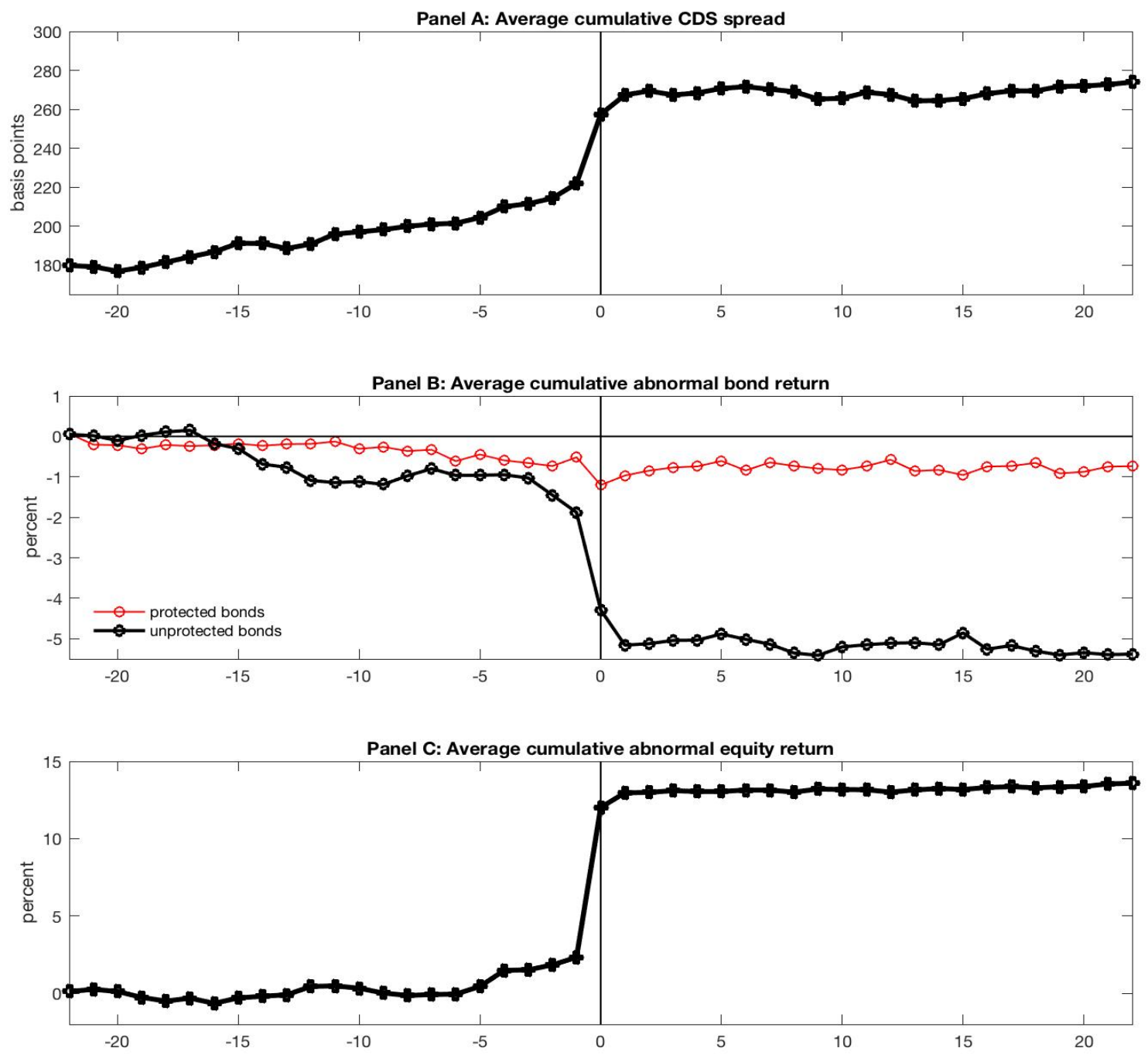

Fig. 3. CDS, bond, and equity returns of the target firm around LBO announcements. Panel A shows the average 5-year CDS spread (based on 42 firms). Panel B shows the cumulative average abnormal percentage log return on the bonds. 'Protected bonds' is based on 43 bonds (issued by 21 firms), while 'unprotected bonds' is based on 187 bonds (issued by 28 firms). Panel $\mathrm{C}$ shows the average abnormal equity return (based on 93 firms). Day 0 is the day the LBO is announced and the time period is 2002-2015. 


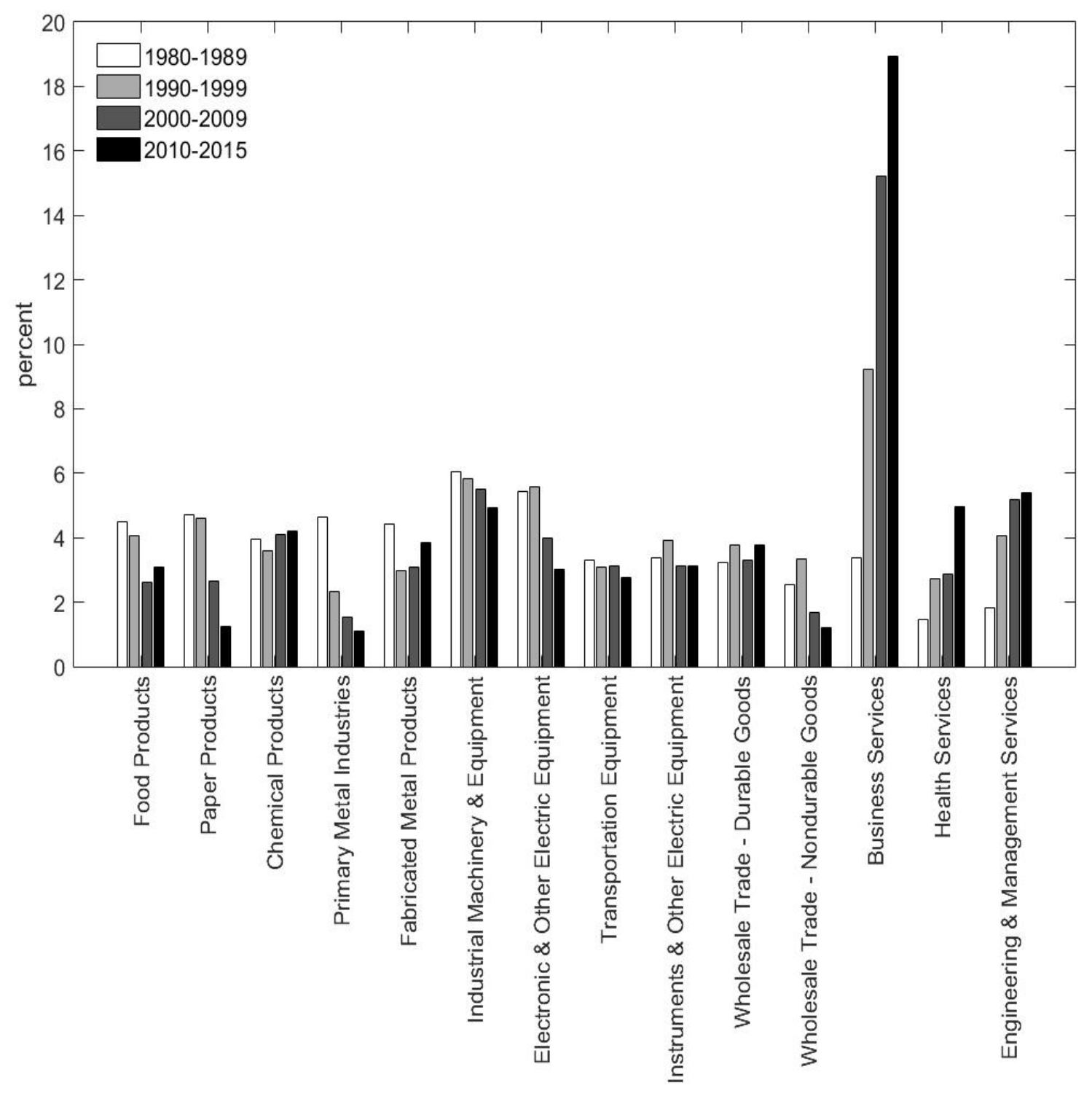

Fig. 4. Industry-level clustering in LBO activity. This figure displays the percentage of LBOs in different 2-digit SIC industries out of the total number of LBOs in the specified time frame. The total number of LBOs are 1419, 1940, 3863, and 3567 in the periods 1980-1989, 1990-1999, 2000-2009 and 2010-2015, respectively. Industries displayed are those for which the percentage was higher than $3 \%$ in at least one of the decades. Data on LBO announcements are retrieved from Thomson One Banker. 

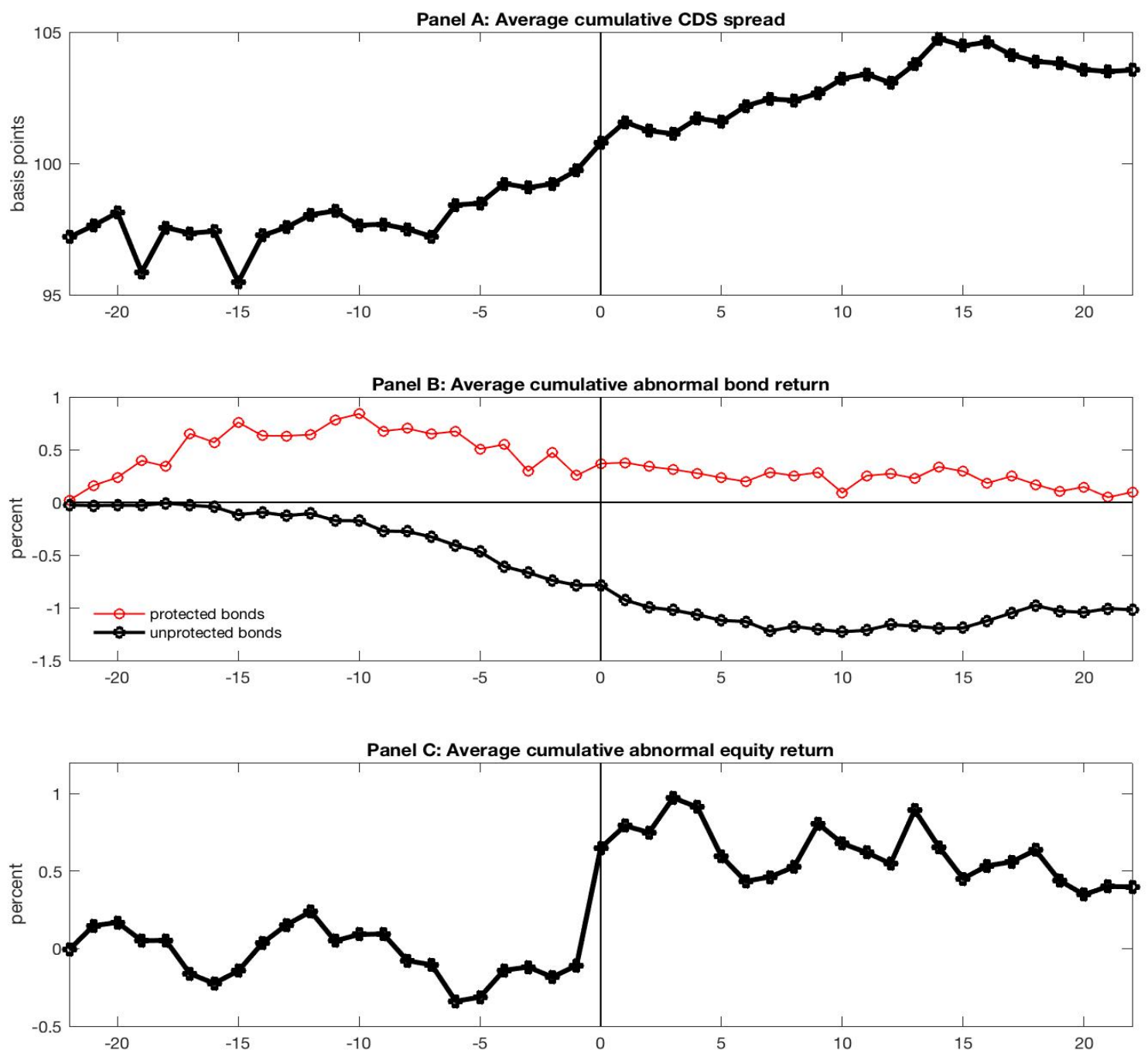

Fig. 5. CDS, bond, and equity returns of other firms in same industry around LBO announcements. Panel A shows the average 5-year CDS spread (based on 462 firms). Panel B shows the cumulative average abnormal percentage log return on the bonds. 'Protected bonds' is based on 73 bonds (issued by 30 firms), while 'unprotected bonds' is based on 1075 bonds (issued by 312 firms). Panel C shows the average abnormal equity return (based on 524 firms). Day 0 is the day the LBO is announced and the time period is $2002-2015$. 


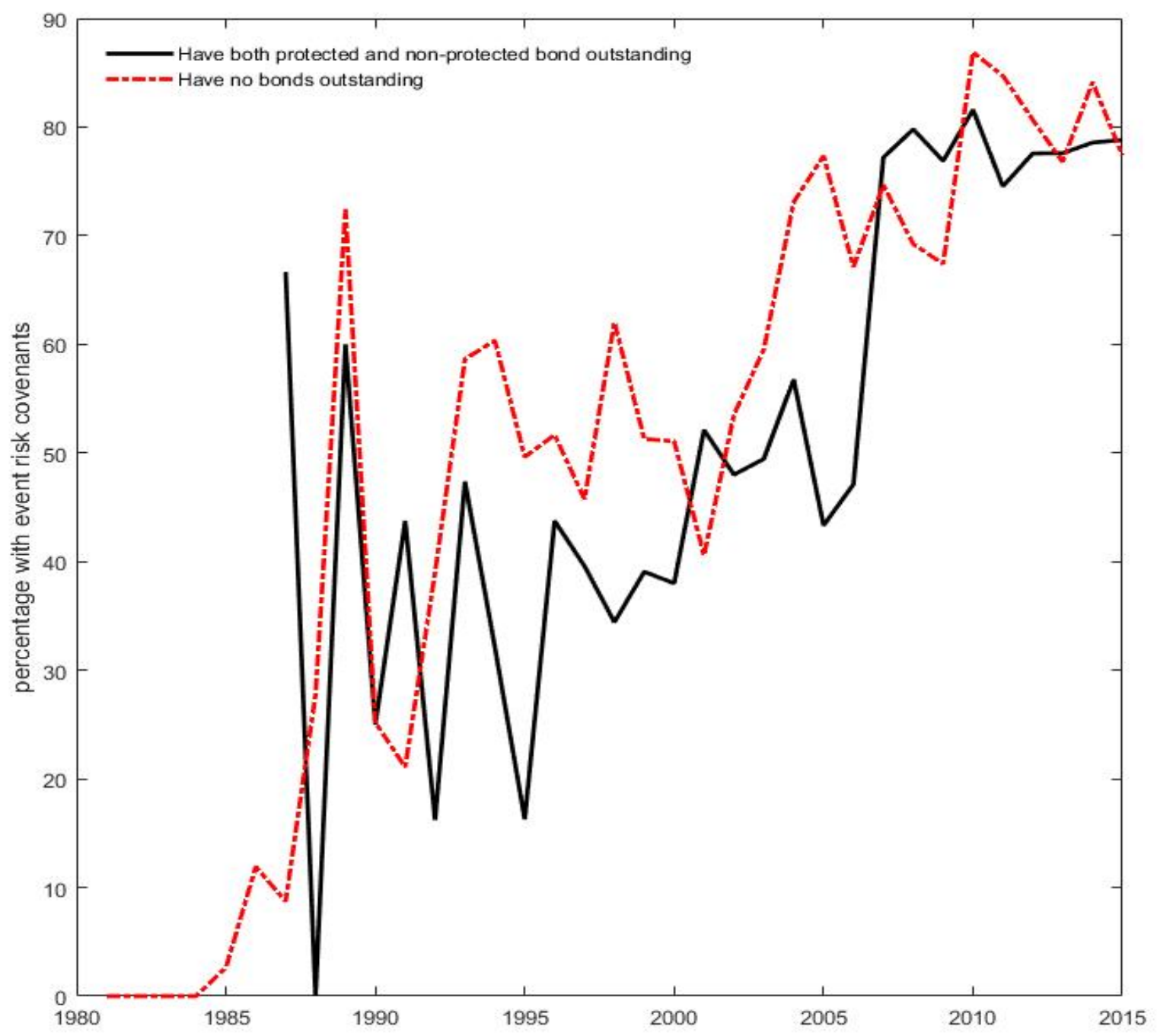

Fig. 6. New bond issues and event risk covenants conditional on past issuance. This figure reports the percentage of new issues with event risk covenants over the years 1980-2015, as retrieved from the Mergent FISD database. The percentage is out of the issues for which information is available in FISD and an issue is marked as having an event risk covenant if the issue has a "change of control put provision". 'Have both protected and non-protected bond outstanding' reflects issues where at bond issuance the issuing firm had at least one protected bond and one unprotected bond outstanding. 'Have no bonds outstanding' refers to the case where the issuing firm had no outstanding bonds at issuance. 

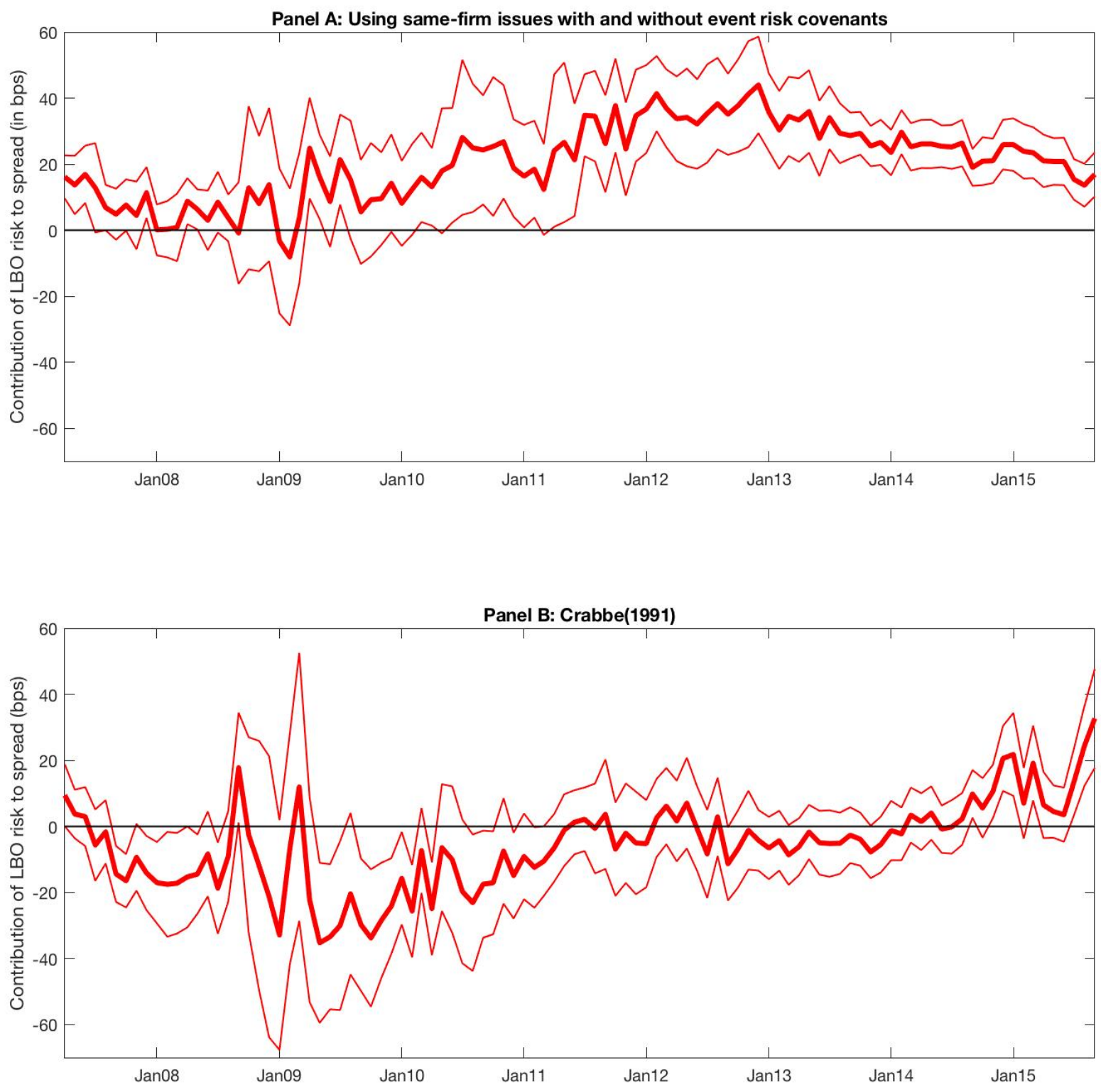

Fig. 7. The contribution of LBO risk to credit spreads estimated using event risk covenants in bonds. We propose a regression approach where we restrict the sample firms to those that have both a bond with an event risk covenant and a bond without. We include firm-fixed effects in monthly regressions of yield spreads on a dummy for event risk covenant inclusion and controls. The dummy is a measure of the contribution of LBO risk to credit spreads. Panel A shows the negative of the monthly regression coefficient, i.e. a positive value in the graph represents a positive contribution of LBO risk to credit spreads. Panel B shows the negative of the monthly coefficient from the regressions in Crabbe(1991), which estimates cross-sectional regressions of corporate bond yield spreads on a dummy for the inclusion of an event risk covenant and controls and here, too, a positive value in the graph represents a positive contribution of LBO risk to credit spreads. Both graphs show a $95 \%$ confidence interval based on the monthly standard deviations in the regressions. 52 


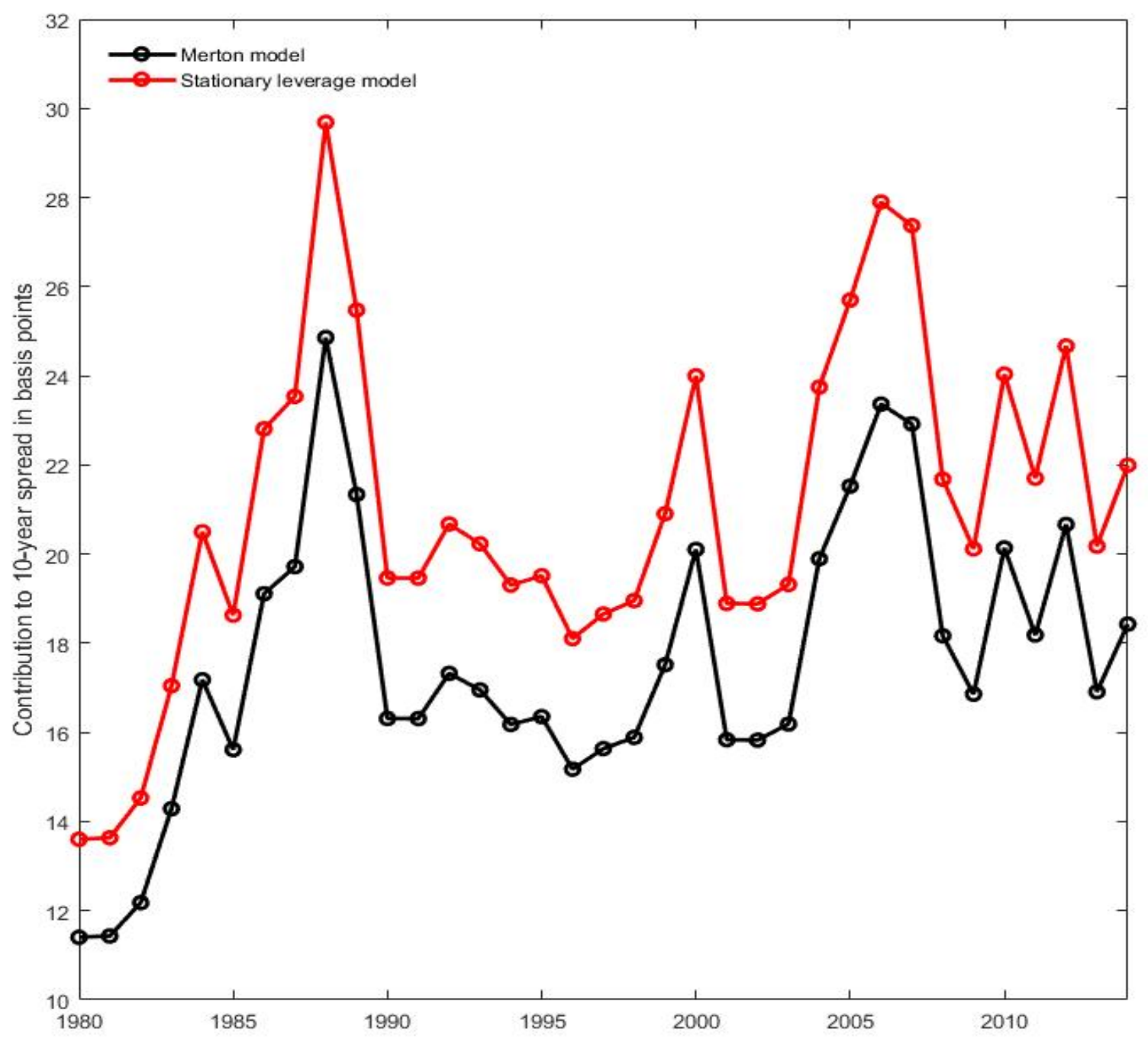

Fig. 8. The contribution of LBO risk to the ten-year credit spread of a typical firm. For a typical firm in the corporate bond market with leverage of $33 \%$ and asset volatility of $24 \%$, we calculate the time-varying contribution of LBO risk to the ten-year credit spread in the structural model outlined in Section 4.3. This figure shows the difference (in basis points) in model-implied credit spreads with and without LBO risk. 